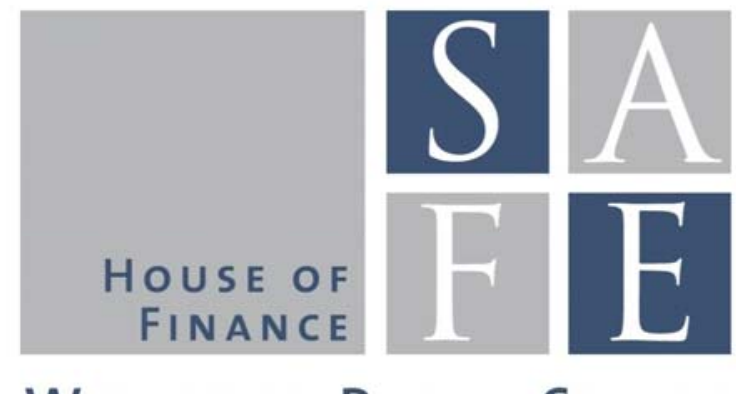

WORKING PAPER SERIES

Adrian Buss - Bernard Dumas - Raman Uppal - Grigory Vilkov

\title{
The Intended and Unintended Consequences of Financial-Market Regulations: A General Equilibrium Analysis
}

SAFE Working Paper No. 124

SAFE I Sustainable Architecture for Finance in Europe A cooperation of the Center for Financial Studies and Goethe University Frankfurt 


\section{Non-Technical Summary}

Financial markets have historically been regulated. This regulation is motivated by the desire to rule out anti-competitive behavior, to prevent agency problems that arise in the presence of asymmetric information, and to limit negative externalities, where the behavior of an individual investor or institution can affect the entire financial system. The recent financial crisis, which has highlighted the negative feedback from financial markets to the real sector, has intensified the debate about the ability of financial-market regulations to stabilize these markets and improve macroeconomic outcomes. We study the intended and unintended consequences of various regulatory measures used to reduce fluctuations in financial and real markets and to improve welfare. The measures we study are the ones that have been proposed by regulators in response to the financial crisis: the Tobin financial-transactions tax, portfolio (short-sale) constraints, and borrowing (leverage) constraints.

For example, on 1 August 2012, France introduced a financial transaction tax of $0.20 \%$; on 25 July 2012, Spain's Comision Nacional del Mercado de Valores (CNMV) imposed a three-month ban on short-selling stocks, while Italy's Consob prohibited short-selling of stocks of 29 banks and insurance companies; and, tighter leverage constraints have been proposed following the subprime crisis: for instance, on 17 October 2008 the European Commissioner, Joaquin Almunia, said: "Regulation is going to have to be thoroughly anti-cyclical, which is going to reduce leverage levels from what we've seen up to now."

Our objective is to evaluate these three regulatory measures within the same dynamic, stochastic general equilibrium model of a production economy, and to compare within a single economic setting, both the intended and unintended effects of these different measures on the financial and real sectors. The kind of questions we address are the following: Of the three regulatory measures we consider, which is most effective in stabilizing financial markets? What exactly is the channel through which each measure works? What will be the impact, intended or unintended, of this measure on other financial variables and the spillover effects on real variables? Would more tightly regulated markets be more stable and increase productivity and welfare?

We have undertaken a general-equilibrium analysis of a production economy with investors who are uncertain about the current state of the economy and disagree in a time-varying way about its expected growth rate. Trading in financial markets allows investors to share laborincome risks. But, financial markets also provide an arena for speculative trading amongst investors who disagree. This speculative trading increases volatility of bond and stock returns and also the volatility of investment growth, increases the equity risk premium, and reduces welfare.

The main finding of our paper is that all three regulatory measures we consider have similar effects on financial and macroeconomic variables: they reduce stock and bond turnovers, reduce the risk-free rate, increase the equity risk premium and stock-return volatility, while 
changing capital investment and output growth. However, because the importance of the bond and stock markets for risk sharing and speculation is different, only those regulatory measures that are able to reduce speculation without hurting risk sharing substantially improve welfare. For example, the borrowing constraint improves welfare because it limits speculation by restricting access to funds needed to implement speculative trading strategies, but has only a marginal effect on risk sharing because borrowing plays a minor role for risk sharing. Similarly, a transaction tax improves welfare because, while it allows for small frequent trades to hedge labor-income risks, it makes large and erratic speculative trades less profitable. In contrast, a limit on stock holdings, such as a short-sale ban, leads to a decrease in welfare because it limits risk sharing severely, while reducing only partially speculative trading. 


\title{
The Intended and Unintended Consequences of
}

\section{Financial-Market Regulations: A General Equilibrium Analysis*}

\author{
Adrian Buss \\ Bernard Dumas \\ Raman Uppal \\ Grigory Vilkov
}

January 25, 2016

\begin{abstract}
In a production economy with trade in financial markets motivated by the desire to share labor-income risk and to speculate, we show that speculation increases volatility of asset returns and investment growth, increases the equity risk premium, and reduces welfare. Regulatory measures, such as constraints on stock positions, borrowing constraints, and the Tobin tax have similar effects on financial and macroeconomic variables. Borrowing limits and a financial transaction tax improve welfare because they substantially reduce speculative trading without impairing excessively risk-sharing trades.
\end{abstract}

Keywords: Tobin tax, borrowing constraints, short-sale constraints, stock market volatility, incomplete markets, differences of opinion.

JEL: G01, G18, G12, E44

\footnotetext{
* Buss is affiliated with INSEAD and can be contacted at Adrian. Buss@insead.edu. Dumas is affiliated with INSEAD, University of Torino, NBER and CEPR and can be contacted at Bernard.Dumas@insead.edu. Uppal is affiliated with Edhec Business School and CEPR and can be contacted at Raman.Uppal@edhec.edu. Grigory Vilkov is affiliated with SAFE and Frankfurt School of Finance \& Management and can be contacted at vilkov@vilkov.net. We appreciate comments and discussions at the November 2015 Carnegie Rochester NYU Conference on Public Policy. We are particularly grateful to our discussant Johan Walden and the editors Marvin Goodfriend and Burton Hollifield. This research benefited from the support of the French Banking Federation Chair on "Banking regulation and innovation" under the aegis of Louis Bachelier laboratory in collaboration with the Fondation Institut Europlace de Finance (IEF) and EDHEC. It benefited also from the support of the AXA Chair in Socioeconomic Risks at the University of Torino. We gratefully acknowledge financial support from the Fondation Banque de France; however, the work in this paper does not necessarily represent the views of the Banque de France. We also gratefully acknowledge research and financial support from the Center of Excellence SAFE, funded by the State of Hessen initiative for research LOEWE. We received helpful comments on this and earlier versions of the manuscript circulated under the title "Comparing Different Regulatory Measures to Control Stock Market Volatility: A General Equilibrium Analysis" from seminar participants at the Bank of England, Bocconi University, Collegio Carlo Alberto, Conference on Behavioral Aspects in Macroeconomics and Finance, Duisenberg School of Finance and Tinbergen Institute, European Finance Association Meetings, European Summer Symposium on Financial Markets, Fédération Bancaire Française, Financial Intermediation Research Society (FIRS) Conference, Fourth India Finance Conference, Ideas Lab Forum at Deutsche Bank, Tenth Journées of the Banque de France Foundation, London Financial Regulation Seminar Series, Sixth Paul Woolley Conference, Rotterdam School of Management, SIFR Conference, University of British Columbia Finance Summer Conference, University of Mannheim, University of Oxford and Oxford-Man Institute, Vienna University of Economics and Business, Western Finance Association Meetings, and the World Finance Conference.
} 


\section{Introduction}

Financial markets have historically been regulated. This regulation is motivated by the desire to rule out anti-competitive behavior, to prevent agency problems that arise in the presence of asymmetric information, and to limit negative externalities, where the behavior of an individual investor or institution can affect the entire financial system. The recent financial crisis, which has highlighted the negative feedback from financial markets to the real sector, has intensified the debate about the ability of financial-market regulations to stabilize these markets and improve macroeconomic outcomes. In this paper, we study the intended and unintended consequences of various regulatory measures used to reduce fluctuations in financial and real markets and to improve welfare. The measures we study are the ones that have been proposed by regulators in response to the financial crisis: the Tobin financial-transactions tax, portfolio (short-sale) constraints, and borrowing (leverage) constraints. ${ }^{1}$

Our objective is to evaluate these three regulatory measures within the same dynamic, stochastic general equilibrium model of a production economy, and to compare within a single economic setting, both the intended and unintended effects of these different measures on the financial and real sectors. ${ }^{2}$ The kind of questions we address are the following: Of the three regulatory measures we consider, which is most effective in stabilizing financial markets? What exactly is the channel through which each measure works? What will be the impact, intended or unintended, of this measure on other financial variables and the spillover effects on real variables? Would more tightly regulated markets be more stable and increase output growth or welfare?

\footnotetext{
${ }^{1}$ For example, on 1 August 2012, France introduced a financial transaction tax of $0.20 \%$; on 25 July 2012, Spain's Comisión Nacional del Mercado de Valores (CNMV) imposed a three-month ban on shortselling stocks, while Italy's Consob prohibited shortselling of stocks of 29 banks and insurance companies; and, tighter leverage constraints have been proposed following the subprime crisis: for instance, on 17 October 2008 the European Commissioner, Joaquin Almunia, said: "Regulation is going to have to be thoroughly anti-cyclical, which is going to reduce leverage levels from what we've seen up to now."For a review of research on the Tobin tax, see Anthony, Bijlsma, Elbourne, Lever, and Zwart (2012) and McCulloch and Pacillo (2011); for a review of the literature on shortsale constraints, see Beber and Pagano (2013); and, for a review of studies on regulatory constraints on leverage, see Crawford, Graham, and Bordeleau (2009).

${ }^{2}$ The importance of relying on a general equilibrium analysis is highlighted in Loewenstein and Willard (2006) and Coen-Pirani (2005), who show that partial-equilibrium analysis can lead to incorrect inferences.
} 
The model we develop to address these questions has two central features. The first is the presence of two distinct motives for trading in financial markets: (i) labor income that is risky, so investors use financial markets for risk sharing; in this case, financial markets improve welfare; (ii) investors disagree about the state of the economy, so investors use financial markets to speculate, which generates "excess volatility" in asset prices that has negative feedback effects on the real sector and reduces welfare. ${ }^{3}$

Second, we study a production economy with endogenous growth, but with an additional risk that originates in financial markets itself, over and above the risk originating in the production system. This additional risk arises from the disagreement amongst investors: because in the eyes of each investor the behavior of the other investor(s) seems fickle, it is seen as a source of risk. It is only in a setting with endogenous production that one can analyze the feedback from this financial-market risk to the real sector, and hence, the impact of financial-market regulation on the real sector. The presence of these regulatory measures implies that in our model financial markets are incomplete.

These features of the model allow us to meet the twin challenge set by Eichenbaum (2010): to model simultaneously (i) heterogeneity in beliefs and persistent disagreement between investors and (ii) financial-market frictions, with risk residing internally in the financial system, rather than externally in the production system. The twin challenges are met here with one stroke because the heterogeneity of investor beliefs we model is a fluctuating, stochastic one so that it constitutes, indeed, an internal source of risk. ${ }^{4}$

The main finding of our paper is that all three regulatory measures we consider have similar effects on financial and macroeconomic variables: they reduce stock and bond turnovers, reduce the risk-free rate, increase the equity risk premium and stock-return volatility, while changing capital investment and output growth. However, because the

\footnotetext{
${ }^{3}$ Both policymakers and academics have recognized the importance of studying models with heterogeneous investors with different beliefs, among others, Hansen (2007), Sargent (2008), Stiglitz (2010), and Hansen (2010), who discuss the implications of the common beliefs assumption (for policy) and the intriguing possibilities of heterogeneous beliefs.

${ }^{4}$ It constitutes, in fact, two internal sources of risk, which are correlated with each other: the extent disagreement is stochastic and the volatility of disagreement is also stochastic (with serial correlation), so that periods of quiescence in the financial market are followed by periods of agitation.
} 
importance of the bond and stock markets for risk sharing and speculation is different, only those regulatory measures that are able to reduce speculation without hurting risk sharing substantially improve welfare. For example, the borrowing constraint improves welfare because it limits speculation by restricting access to funds needed to implement speculative trading strategies, but has only a marginal effect on risk sharing because borrowing plays a minor role for risk sharing. Similarly, a transaction tax improves welfare because, while it allows for small frequent trades to hedge labor-income risks, it makes large and erratic speculative trades less profitable. In contrast, a limit on stock holdings, such as a short-sale ban, can lead to a decrease in welfare because it limits risk sharing severely, while reducing only partially speculative trading.

Our work is related to several strands of the literature. The literature that is closest is the work on the remedies to the recent financial crisis and on regulation of financial markets in general. For example, Geanakoplos and Fostel (2008) and Geanakoplos (2009) study the effect of exogenous collateral restrictions on the supply of liquidity, while Krishnamurthy (2003) studies the way credit constraints can lead to amplification of shocks in the economy. ${ }^{5}$ Ashcraft, Gârleanu, and Pedersen (2010) compare the effectiveness of different monetary tools. Our analysis is related also to the historic debate on the stabilizing or destabilizing effects of speculation (Alchian (1950) and Friedman (1953)).

Our model is closely related to the literature on economies with disagreement and learning, including the literature on "behavioral equilibrium theory", in the sense of Barberis, Shleifer, and Vishny (1998), Daniel, Hirshleifer, and Subrahmanyam (1998), and Hong and Stein (1999). Our paper is linked to the work by Scheinkman and Xiong (2003), who study whether disagreement can explain overvaluation in asset markets for an exchange economy with risk-neutral agents; Panageas (2005) who studies the implications of this model for physical investment; and, Dumas, Kurshev, and Uppal (2009), who have a similar setting, except that all investors are risk-averse. While in these three papers, the stochastic growth rate is unobservable, we use a Hidden Markov model in which the

\footnotetext{
${ }^{5}$ See also Chabakauri (2013a,b), who studies the effect of portfolio constraints in an exchange economy where agents are heterogeneous with respect to their preferences but have the same beliefs.
} 
state of the economy is unobservable. As in our paper, investors use publicly observable variables to update their beliefs and disagreement stems from the use of a public signal. That is, investors disagree because they steadfastly believe that the correlation between the signal and the fundamental is non-zero when, in fact, it is zero, and, accordingly, update their beliefs differently. Ours is the first paper that models jointly heterogeneous beliefs, production, stochastic labor income and, most importantly, financial regulation. In addition, because of perfect symmetry across investors, in our model both investors survive in the long-run and so we get a non-degenerate long-run wealth distribution.

Having a model with both production and disagreement is important for evaluating the real effects of disagreement and of the imposed regulatory measures, and in this respect our work is similar to Baker, Hollifield, and Osambela (2016). Their paper shows theoretically that static disagreement impacts a number of real variables such as aggregate investment, consumption, and output, which is consistent with our results; however, the disagreement process in our model is dynamic so that we do not have an a priori optimistic or pessimistic trader, and in addition we also study the effects of imposing various regulatory measures. Li and Loewenstein (2015) also study production and disagreement, showing that extraneous risk can affect productive decisions, leading to a decrease or an increase in real investment and asset prices. Arif and Lee (2014) show empirically that real variables such as corporate investments are affected by beliefs not justified by fundamentals. An earlier study by Detemple and Murthy (1994) also analyzes a production economy with disagreement, but with log utility and without capital adjustment costs; because of these assumptions, disagreement has no effect on many variables of interest.

In our model, differences in beliefs and market incompleteness complicate the evaluation of the welfare effects of regulatory measures. There are several papers in the recent literature that discuss the challenges that arise in evaluating welfare in such settings and propose various solutions. These papers include: Fedyk, Heyerdahl-Larsen, and Walden (2013), Brunnermeier, Simsek, and Xiong (2014), Heyerdahl-Larsen and Walden (2014), and Blume, Cogley, Easley, Sargent, and Tsyrennikov (2015). 
The rest of the paper is organized as follows. In Section 2, we describe our modeling choices for the real and financial sectors, and the preferences and beliefs of investors. In Section 3, we characterize equilibrium in our economy. In Section 4, we calibrate the model and explain the effects of disagreement. The implications of financial regulation are described in Section 5. Various robustness experiments are discussed in Section 6 and we conclude in Section 7. Technical results and details of the solution method are relegated to the online appendix.

\section{The Model}

In this section, we describe the features of the model we study as well as the implementation of the regulatory measures. The economy is a simple production economy with endogenous growth. Investors in the economy receive wages, subject to idiosyncratic shocks, and use a bond as well as a stock to hedge their income risk, creating a risk-sharing motive for trade. At the aggregate level, there are two sources of risk: a productivity shock and a public signal that is possibly interpreted differently by the investors, leading to disagreement, which generates a speculative motive for trade in the two financial assets. In the rest of this section, we give the details of the model.

\subsection{Basic Model}

Time is assumed to be discrete, denoted by $t$, ranging from $t=1$ to the terminal date $t=T$. At each point in time $t$, there exist $J$ possible future states. There exists a single consumption and investment good that is produced by a representative firm. The firm employs an ' $Z K$ '-production technology. Accordingly, the economy is growing through capital accumulation at an endogenous growth rate. Specifically, output $Y_{t}$ is given by

$$
Y_{t}=Z_{t} \times K_{t} \times L_{t}^{1-\alpha}
$$

where $Z_{t}$ denotes stochastic productivity, as specified below, $K_{t}$ denotes the capital stock, and $L_{t}$ denotes the labor employed by the firm. As investors do not derive utility from 
leisure, in equilibrium they provide on aggregate one unit of labor: $L_{t}=1$. The firm can accumulate capital through investment $I_{t}$, subject to quadratic adjustment costs:

$$
K_{t+1}=(1-\delta) K_{t}+I_{t}-\frac{\xi}{2}\left(\frac{I_{t}}{K_{t}}\right)^{2} K_{t}
$$

where $\delta$ denotes the rate of depreciation and $\xi>0$ is the adjustment cost parameter.

Denoting by $W_{t}$ the wages paid to the workers and by $q_{t+1, j}$ the state price of the firm's owners for state $j$, which is given by the ownership-weighted state prices of the individual investors, managers of the firm choose investment $I_{t}$ and labor $L_{t}$ to maximize the value $\mathcal{P}_{t}\left(K_{t}\right)$ of the firm to its owners, given by the present value of dividends $D_{t}=Y_{t}-I_{t}-L_{t} W_{t}$ :

$$
\mathcal{P}_{t}\left(K_{t}\right)=\max _{I_{t}, L_{t}}\left(Y_{t}-I_{t}-L_{t} W_{t}\right)+\sum_{j=1}^{J} q_{t+1, j} \mathcal{P}_{t+1, j}\left(K_{t+1}\right),
$$

subject to the law-of-motion of capital in (2).

There exist two groups of investors, $i=\{1,2\}$, that derive utility from consumption $c_{i, t}$. The investors receive stochastic wages by supplying labor to the firm. Specifically, the first investor can supply $e_{1, t} \in\left\{e_{1, u}, e_{1, d}\right\}$ units of labor with $e_{1, t}$ following a simple Markov chain with transition matrix $E$. The second investor can supply $e_{2, t}=1-e_{1, t}$ units so that, on aggregate, investors always supply one unit of labor to the firm.

The investors can invest in a risk-free one-period bond, which is in zero net supply and pays one unit of the consumption good, as well as in a stock, which is available in unit supply and that represents a claim to the dividends $D_{t}$ of the representative firm. We denote the time- $t$ price of the bond by $B_{t}$ and of the stock by $S_{t}$ and assume that investors are initially endowed with half a share of the stock and have no debt.

While our main analysis focuses on the case of time-separable (CRRA) preferences, in the robustness section we study non-separable (recursive) preferences. We, therefore, specify preferences directly in the general Epstein and Zin (1989) and Weil (1990) form, which nests time-separable utility, but allows one to separate risk aversion, which drives the desire to smooth consumption across states, from elasticity of intertemporal substi- 
tution, which drives the desire to smooth consumption over time. We assume that the investors have identical preference parameters, but potentially disagree about the likelihood of future states. They choose consumption $c_{i, t}$, investment in the bond $\theta_{i, t}^{B}$ and in the stock $\theta_{i, t}^{S}$, both denoted in number of shares, to maximize their lifetime utility

$$
V_{i, t}=\left[(1-\beta) c_{i, t}^{1-\frac{1}{\psi}}+\beta \mathbb{E}_{t}^{i}\left[V_{i, t+1}^{1-\gamma}\right]^{\frac{1}{\phi}}\right]^{\frac{\phi}{1-\gamma}}
$$

where $\mathbb{E}_{t}^{i}$ is the conditional expectation at time $t$ under the investor's subjective probability measure, $\beta$ is the factor of time preference, $\gamma>0$ is the coefficient of relative risk aversion, $\psi>0$ is the elasticity of intertemporal substitution, and $\phi=\frac{1-\gamma}{1-1 / \psi}$. This optimization is subject to a flow budget equation

$$
c_{i, t}+\theta_{i, t}^{B} B_{t}+\theta_{i, t}^{S} S_{t}=\theta_{i, t-1}^{B}+\theta_{i, t-1}^{S}\left(D_{t}+S_{t}\right)+e_{i, t} W_{t}
$$

where the left-hand side gives the uses of funds and the right-hand side gives the sources of funds - the payout received from holding the bond, the stock, and from wages.

Uncertainty in the economy is generated by a Hidden Markov model. ${ }^{6}$ Specifically, we assume that there exist two hidden (unobservable) states in the economy, $x_{t} \in\{1,2\}$, conveniently called "expansion" and "recession". Transitions between the hidden states are governed by a Markov process with row-stochastic $2 \times 2$ transition matrix $A$. Initially, i.e., at time 1, the economy is equally likely to start in either of the two hidden states.

While the hidden state is not observable, investors observe stochastic technology growth $z_{t}=\frac{Z_{t}}{Z_{t-1}}-1$. We assume that there are two stochastic growth rates: $z_{t} \in\left\{u\left(Z_{t}\right)\right.$, $\left.d\left(Z_{t}\right)\right\}$ with $u\left(Z_{t}\right)>d\left(Z_{t}\right){ }^{7}$ To ensure a stationary distribution for productivity, the productivity growth rates depend on the current level of productivity $Z_{t}$. Specifically, we assume that they depend on the current level of productivity in the following way:

$$
u\left(Z_{t}\right)=\bar{u}+\left(\bar{Z}-Z_{t}\right) \times \nu, \quad \text { and } \quad d\left(Z_{t}\right)=\bar{d}+\left(\bar{Z}-Z_{t}\right) \times \nu,
$$

\footnotetext{
${ }^{6}$ For a detailed tutorial on Hidden Markov models, see Rabiner (1989).

${ }^{7}$ For simplicity of notation, the dependency on $Z_{t}$ is typically not written explicitly.
} 
where $\bar{u}>0$ and $\bar{d}<0$ denote the growth rates if $Z_{t}$ is equal to the mean level of productivity $\bar{Z}$. The term $\left(\bar{Z}-Z_{t}\right) \times \nu$ shifts both growth rates upwards (downwards) if $Z_{t}$ is below (above) the mean, reverting productivity back towards the mean. ${ }^{8}$

In addition, investors observe a binary signal $s_{t} \in\left\{s_{1}, s_{2}\right\}$. In total, this implies four possible future observations $o_{t} \in\left\{\left(u, s_{1}\right),\left(u, s_{2}\right),\left(d, s_{1}\right),\left(d, s_{2}\right)\right\}$ which we conveniently denote as $o_{t} \in\{1, \ldots, 4\}$. A $2 \times 4$ row-stochastic observation matrix $\mathcal{O}$ with elements $\mathcal{O}_{x, o}=P\left(o_{t}=o \mid x_{t}=x\right)$ describes the probability of observing $o$ if the economy is currently in the hidden state $x$.

Given this probabilistic relation between the observations and the hidden states, investors can use the time series of observable variables $\mathbb{O}_{t}=\left(o_{1}, \ldots, o_{t}\right)$ to infer the probability $p_{t, x}=P\left(x_{t}=x \mid \mathbb{O}_{t}\right)$ for being currently in hidden state $x$. Specifically, given last period's perceived state probabilities $p_{t-1, x},{ }^{9}$ applying Bayes' rule shows that investors recursively update their beliefs about the state of the economy as follows: ${ }^{10}$

$$
\alpha_{t, x}=\left(\sum_{n=1}^{2} p_{t-1, x} A_{n, x}\right) \mathcal{O}_{x, o_{t}}, \quad \text { and } \quad p_{t, x}=\alpha_{t, x}\left(\sum_{n=1}^{2} \alpha_{t, n}\right)^{-1} .
$$

Intuitively, given a new observation $o_{t}$ investors first compute for each state the joint likelihood $\alpha_{t, x}$ of currently being in state $x$ and observing $o_{t}$. For this, investors compute the likelihood of transitioning into state $x$ at $t$, taking as given last period's state probabilities $p_{t-1 \text {, }}$ and the transition probabilities in $A$. Based on the likelihood of a state $x$, one can then compute the joint likelihood of the state and of observing $o_{t}$ using the probabilistic relation encoded in $\mathcal{O}$. Secondly, investors normalize the joint likelihoods for all states to arrive at the probability $p_{t, x}$.

For our model, we specify a specific structure for the observation matrix $\mathcal{O}$ : we assume that it is more likely to observe high productivity growth $u$ than low productivity growth

\footnotetext{
${ }^{8}$ This implies a minimum level of productivity of $\bar{Z}+\frac{\bar{d}}{\nu}$, as for this level of productivity both growth rates $u\left(Z_{t}\right)$ and $d\left(Z_{t}\right)$ would be greater or equal to zero. Similarly, it implies a maximum level of productivity of $\bar{Z}+\frac{\bar{u}}{\nu}$.

${ }^{9}$ We assume that investors' priors $\pi_{x}=p_{0, x}$, coincide with the initial distribution of the states.

${ }^{10}$ Technically, this "forward algorithm" is the nonlinear analog for discrete-time discrete-state Markov chains, of the Kalman filter, which is applicable to linear stochastic processes. See Baum, Petrie, Soules, and Weiss (1970) and Rabiner (1989).
} 
$d$ if the economy is in the first hidden state, i.e., $p=P\left(z_{t}=u \mid x_{t}=1\right)>P\left(z_{t}=\right.$ $d \mid x_{t}=1$ ), leading to the notion of an expansionary state, and vice versa for the recession state. Accordingly, the realizations of productivity growth provide the investors with valuable information about the current hidden state of the economy, with the parameter $p$ describing the 'accuracy' with which high growth is related to the expansionary state, e.g., for $p=1$, the investors could perfectly infer the hidden state from the observed productivity growth.

In contrast, we assume that the signal realization is unrelated to the hidden state, i.e., $P\left(s_{t}=s_{1} \mid x_{t}=1\right)=P\left(s_{t}=s_{2} \mid x_{t}=1\right)=P\left(s_{t}=s_{1} \mid x_{t}=2\right)=P\left(s_{t}=s_{2} \mid x_{t}=2\right)=1 / 2$. Accordingly, the realization of the signal does not provide any information about the current hidden state of the economy.

Putting these assumptions together and imposing symmetry, the matrix $\mathcal{O}$ that governs the probabilities of the realizations conditional on the hidden states is given by:

$$
\mathcal{O}=\left[\begin{array}{cccc}
p / 2 & p / 2 & (1-p) / 2 & (1-p) / 2 \\
(1-p) / 2 & (1-p) / 2 & p / 2 & p / 2
\end{array}\right]
$$

Investors might disagree about the information contained in the signal. Specifically, we assume that investors make inferences about the hidden states using the common Markov transition matrix $A$, but an investor-specific observation matrix $\mathcal{O}^{i}$, implying different Bayesian updating rules, so that they will agree to disagree, and will not converge to some common beliefs. The observation matrix $\mathcal{O}^{i}$ is modeled as a combination of the 'true' observation matrix $\mathcal{O}$, given in equation (8) and of an observation matrix, $\mathcal{O}^{\text {sig, } i}$, that delivers a perfect correlation between the signal and the hidden state:

$$
\mathcal{O}^{i}=(1-w) \times \mathcal{O}+w \times \mathcal{O}^{s i g, i}
$$

where $w$ denotes the weight that the investors puts on the signal, i.e., differs from the true matrix $\mathcal{O}$. The investor-specific observation matrices are given by:

$$
\mathcal{O}^{\text {sig, } 1}=\left[\begin{array}{cccc}
1 / 2 & 0 & 1 / 2 & 0 \\
0 & 1 / 2 & 0 & 1 / 2
\end{array}\right] \quad \text { and } \quad \mathcal{O}^{\text {sig, }, 2}=\left[\begin{array}{cccc}
0 & 1 / 2 & 0 & 1 / 2 \\
1 / 2 & 0 & 1 / 2 & 0
\end{array}\right]
$$


That is, if the first investor were to put all his weight on his signal matrix $\mathcal{O}^{\text {sig, },}$, he would believe that a realization of signal $s_{1}\left(s_{2}\right)$ would imply that the economy could only be in hidden state 1 (2), independent of the technology growth realization. Similarly for investor 2 , but interchanging the roles played by the signals, i.e., signal $s_{1}\left(s_{2}\right)$ would imply hidden state 2 (1). Accordingly, the more weight the investors put on their individual observation matrices, the more they disagree.

\section{$2.2 \quad$ Regulatory Measures}

We now describe the regulatory measures we study. First, we consider a portfolio constraint for the investors' stock holdings:

$$
\theta_{i, t}^{S} \geq \rho ; \quad \forall i
$$

This regulatory measure places a lower limit on each investor's stock holdings. The higher is $\rho$, with $\rho \leq 0.5$, the more stringent is the constraint. Short-sale constraints are a special case of this portfolio constraint for $\rho=0$.

Secondly, we study a borrowing constraint that limits the amount of borrowing:

$$
\theta_{i, t}^{B} \times B_{t} \geq \kappa \times Y_{t} \quad \forall i
$$

This regulatory measure limits the investors' ability to take on leverage, measured relative to total output in the economy. As both output and the stock market are homogeneous in capital $K_{t}$, this regulatory measure implicitly limits borrowing also relative to the value of the stock market. A higher $\kappa$ (with the restriction that $\kappa \leq 0$ ) reduces the amount of leverage possible, making the constraint more stringent.

Finally, we analyze a Tobin tax, implemented as a transaction tax proportional to the value of a trade in the stock market. To remove income effects of this tax, we assume that the taxes paid by the investors are redistributed in a lump-sum fashion after the investors have made their optimization decisions for that date. The implementation of the Tobin tax results in the following flow budget equation for each investor $i$ :

$$
c_{i, t}+\theta_{i, t}^{B} B_{t}+\theta_{i, t}^{S} S_{t}+\tau \times\left|\theta_{i, t}^{S}-\theta_{i, t-1}^{S}\right| S_{t}=\theta_{i, t-1}^{B}+\theta_{i, t-1}^{S}\left(D_{t}+S_{t}\right)+e_{i, t} W_{t}+\chi_{i, t},
$$


where $\tau$ denotes the rate of the transaction tax and $\chi_{i, t}$ captures the lump-sum redistribution. As the rate $\tau$ increases (with the restriction that $\tau \geq 0$ ), the cost for trading the stock increases, making the constraint more stringent.

\section{Equilibrium}

In this section, we define the equilibrium in our economy. We then describe the first-order conditions that characterize equilibrium in the basic (unregulated) economy. Next, we discuss the changes to the first-order conditions introduced by the different regulatory measures. We conclude with a short description of the solution method. ${ }^{11}$

\subsection{Definition of Equilibrium}

Equilibrium in the economy is defined as a set of consumption policies $c_{i, t}$ and portfolio policies $\theta_{i, t}^{\{B, S\}}$ of the two investors, and investment and labor policies, $I_{t}, L_{t}$, of the representative firm, along with the resulting price processes for the two financial assets, $B_{t}$, $S_{t}$, such that the consumption policy of each investor maximizes her lifetime utility; that this consumption policy is financed by the portfolio policy; the portfolio policy satisfies potential constraints imposed by regulation; that the investment policies maximize firm value; and that the bond, stock, and goods market clear in each state across all dates.

\subsection{Equilibrium in the Unregulated Economy}

We now describe the system of first-order conditions that characterizes the equilibrium in the economy without financial regulation. The objective of the firm is to choose investment $I_{t}$ and labor $L_{t}$ to maximize its value, given in equation (3), subject to the law-of-motion of capital, as outlined in equation (2). The first-order condition with respect to $L_{t}$ together with the fact that in equilibrium investors will, on aggregate, always supply one unit of labor, results in $W_{t} \times L_{t}=(1-\alpha) Y_{t}$. That is, a constant

\footnotetext{
${ }^{11}$ Detailed derivations along with details of the numerical procedure are provided in an online appendix.
} 
fraction $(1-\alpha)$ of output is paid as wages, so that we can rewrite the dividends paid by the firm as $D_{t}=\alpha Y_{t}-I_{t}$. The first-order condition with respect to investment $I_{t}$ is then given by:

$$
\left(1-\xi \frac{I_{t}}{K_{t}}\right) \times \sum_{j=1}^{J} q_{t+1, j}\left(\alpha \times Z_{t+1, j}+\frac{1-\delta+\frac{\xi}{2}\left(\frac{I_{t+1, j}}{K_{t+1}}\right)^{2}}{1-\xi \frac{I_{t+1, j}}{K_{t+1}}}\right)=1
$$

where $q_{t+1, j}$ denotes the firms' owners' state prices, as described in the model section, and the capital accumulation equation is given by: $K_{t+1}=(1-\delta) K_{t}+I_{t}-\frac{\xi}{2}\left(\frac{I_{t}}{K_{t}}\right)^{2} K_{t}$.

The objective of each investor $i$ is to maximize lifetime utility given in (4), subject to the flow budget equation (5), by choosing consumption, $c_{i, t}$, and the portfolio position $\theta_{i, t}^{\{B, S\}}$ in each of the two financial assets. The first-order conditions that characterize this optimization problem are given by the usual flow budget equation in (5) and the 'kernel conditions' that equate the prices of the discount $B_{t}$ and the stock $S_{t}$ across investors:

$$
\begin{aligned}
\mathbb{E}_{t}^{1}\left[\frac{M_{1, t+1}}{M_{1, t}}\right] & =\mathbb{E}_{t}^{2}\left[\frac{M_{2, t+1}}{M_{2, t}}\right], \\
\mathbb{E}_{t}^{1}\left[\frac{M_{1, t+1}}{M_{1, t}} \times\left(S_{t+1}+D_{t+1}\right)\right] & =\mathbb{E}_{t}^{2}\left[\frac{M_{2, t+1}}{M_{2, t}} \times\left(S_{t+1}+D_{t+1}\right)\right],
\end{aligned}
$$

where $\frac{M_{i, t+1}}{M i, t}$ denotes the investors' pricing kernel for Epstein-Zin-Weil utility:

$$
\frac{M_{i, t+1}}{M_{i, t}}=\beta\left(\frac{V_{i, t+1}^{1-\gamma}}{\mathbb{E}_{t}^{i}\left[V_{i, t+1}^{1-\gamma}\right]}\right)^{\frac{\frac{1}{\psi}-\gamma}{1-\gamma}}\left(\frac{c_{i, t+1}}{c_{i, t}}\right)^{-\frac{1}{\psi}}
$$

Finally, for financial markets and the commodity market to clear, we need that supply should equal demand for the bond and the stock, and that aggregate consumption and capital expenditures equal the firm's output: ${ }^{12}$

$$
\theta_{1, t}^{B}+\theta_{2, t}^{B}=0 ; \quad \theta_{1, t}^{S}+\theta_{2, t}^{S}=1 ; \quad \text { and } \quad Y_{t}=c_{1, t}+c_{2, t}+I_{t}
$$

\footnotetext{
${ }^{12}$ By Walras's law financial-market clearing implies goods market clearing, rendering the last equation redundant.
} 
One can show that the solution of this system of equations is homogenous of degree one in the level of capital, so that one needs to solve only the equation system for $K_{t}=1$, with the solutions for other levels of capital following from this.

\subsection{Equilibrium with Regulatory Measures}

In this section, we discuss the changes to the characterization of equilibrium when regulatory measures are introduced. ${ }^{13}$ First, note that financial regulation does not affect the optimization problem of the firm directly, i.e., the first-order condition (14) is unchanged. However, because financial regulation will affect the investors' stock holdings, it will implicitly affect the optimization problem of the firm through changes in the state prices of the firms' owners. In contrast, the first-order conditions for each individual investor's optimization problem will be affected by the regulatory measures, as we explain below.

For the portfolio constraint on the stock, described in equation (11), the kernel condition of the stock changes to:

$$
\frac{1}{1-R_{1, t}^{S}} \mathbb{E}_{t}^{1}\left[\frac{M_{1, t+1}}{M_{1, t}}\left(S_{t+1}+D_{t+1}\right)\right]=\frac{1}{1-R_{2, t}^{S}} \mathbb{E}_{t}^{2}\left[\frac{M_{2, t+1}}{M_{2, t}}\left(S_{t+1}+D_{t+1}\right)\right],
$$

where $R_{i, t}^{S}$ denotes the investors' shadow price associated with the constraint. In addition, we get the complementary slackness conditions, and associated inequality conditions:

$$
R_{i, t}^{S} \times\left(\theta_{i, t}^{S}-\rho\right)=0 ; \quad R_{i, t}^{S} \geq 0 ; \quad \theta_{i, t}^{S} \geq \rho .
$$

In the case of the borrowing constraint in (12), the bond's kernel condition becomes:

$$
\frac{1}{1-R_{1, t}^{B}} \times \mathbb{E}_{t}^{1}\left[\frac{M_{1, t+1}}{M_{1, t}}\right]=\frac{1}{1-R_{2, t}^{B}} \times \mathbb{E}_{t}^{2}\left[\frac{M_{2, t+1}}{M_{2, t}}\right]
$$

where $R_{i, t}^{B}$ denotes the shadow price associated with the constraint for each investor. Moreover, we get the complementary slackness, and associated inequality conditions:

$$
R_{i, t}^{B} \times\left(\theta_{i, t}^{B} B_{t}-\kappa Y_{t}\right)=0 ; \quad R_{i, t}^{S} \geq 0 ; \quad \theta_{i, t}^{B} B_{t} \geq \kappa Y_{t}
$$

\footnotetext{
${ }^{13}$ In all three cases the homogeneity of degree one in capital is preserved, simplifying the solution.
} 
Finally, the Tobin tax changes the budget equations and the stock's pricing kernel:

$$
\begin{gathered}
c_{i, t}+\theta_{i, t}^{B} B_{t}+\theta_{i, t}^{S} S_{t}+\tau \times\left(\hat{\theta}_{i, t}^{S}+\check{\theta}_{i, t}^{S}\right) S_{t}=\theta_{i, t-1}^{B}+\theta_{i, t-1}^{S}\left(D_{t}+S_{t}\right)+e_{i, t} W_{t}+\chi_{i, t}, \\
\frac{1}{R_{1, t}^{T T}} \mathbb{E}_{t}^{1}\left[\frac{M_{1, t+1}}{M_{1, t}}\left(R_{1, t+1}^{T T} S_{t+1}+D_{t+1}\right)\right]=\frac{1}{R_{2, t}^{T T}} \mathbb{E}_{t}^{2}\left[\frac{M_{2, t+1}}{M_{2, t}}\left(R_{2, t+1}^{T T} S_{t+1}+D_{t+1}\right)\right],
\end{gathered}
$$

where $R_{i, t}^{T T}$ denotes the shadow price associated with stock transactions and $\hat{\theta}_{i, t}^{S} \geq 0$ as well as $\check{\theta}_{i, t}^{S} \geq 0$ denote the number of shares sold and bought, respectively, which are linked to the investors' stock holdings through $\theta_{i, t}^{S}=\theta_{i, t-1}^{S}-\hat{\theta}_{i, t}^{S}+\check{\theta}_{i, t}^{S} \cdot{ }^{14}$ The associated complementary slackness and inequality conditions are given by:

$$
\begin{gathered}
\left(-R_{i, t}^{T T}+1+\tau\right) \times \check{\theta}_{i, t}^{S}=0 ; \quad\left(-R_{i, t}^{T T}+1-\tau\right) \times \hat{\theta}_{i, t}^{S}=0 \\
(1-\tau) \leq R_{i, t}^{T T} \leq(1+\tau) ; \quad \check{\theta}_{i, t}^{S} \geq 0 ; \quad \hat{\theta}_{i, t}^{S} \geq 0 .
\end{gathered}
$$

\subsection{Numerical Algorithm}

We solve for the equilibrium in the economy using an extension of the algorithm presented in Dumas and Lyasoff (2012), who show how one can identify the equilibrium in a recursive fashion for a frictionless exchange economy with incomplete financial markets.

Specifically, when markets are incomplete, one must solve for consumption and portfolio policies simultaneously, e.g., by solving simultaneously the entire set of equilibrium conditions for all states across all dates, in which case the number of equations grows exponentially with the number of periods, so that a recursive approach is preferable. However, the problem in solving this system of equations recursively in a general-equilibrium setting is that the current consumption and portfolio choices depend on the prices of assets, which depend on future consumption. Thus, to solve these equations, one would need to iterate backward and forward until the equations for all the nodes on the tree are satisfied. Dumas and Lyasoff (2012) address this problem by proposing a "time-shift" whereby at date $t$ one solves for the optimal portfolio for date $t$ but the optimal consumption for date $t+1$, instead of the optimal consumption for date $t$. Using this insight

\footnotetext{
${ }^{14}$ Using the number of shares bought and sold allows one to replace the absolute value operator, making the problem more suitable for numerical optimization.
} 
allows one to write the system of equations so that it is recursive and backward only. After solving the dynamic program recursively up to the initial date, one can undertake a simple single "forward step" for each simulated path of the underlying processes to determine the equilibrium quantities.

In this paper, we extend the algorithm to a production economy, where output in the economy is endogenous. This adds the optimality condition of the firm. In addition, we extend the algorithm to handle learning given by a Hidden Markov model, which requires one to keep track of each investor's inferred probabilities for the hidden states, for which we create an endogenous state variable on a grid. ${ }^{15}$ In the economy with regulations, one needs to make the additional changes to the system of equations and choice variables. These changes are explained in the online appendix and in Buss and Dumas (2015).

\section{Analysis of the Unregulated Economy}

In this section, we discuss the unregulated economy. First, we explain how we calibrate the model. Next, we investigate how fundamental trading, motivated by the desire to share labor-income risk, and speculative trading, driven by disagreement between investors, influence financial markets, the real economy, and welfare.

\subsection{Calibration}

For the quantitative analysis, we calibrate the model at an annual frequency to match several stylized facts of the U.S. economy. For this, we approximate the infinite-horizon solution of the economy by increasing the horizon $T$ until the interpolated functions that are carried backwards are no longer changing. We then simulate 25, 000 paths of the economy for 200 years. Given the perfect symmetry between the two investors (described below), the distribution of the endogenous state variables - the first investor's consumption share - converges to a steady-state after about 150 years. Specifically, both

\footnotetext{
${ }^{15}$ These state variables take a discrete, recurrent set of numerical values.
} 
investors survive in the long-run and the distribution of the consumption share of the first investor is nicely distributed around the mean of $50 \%$. The results presented below are based on the remaining 50 years, i.e., drawing from the stationary distribution. ${ }^{16}$

In the base case, we assume that investors have identical preferences of the CRRA type, i.e., we restrict the parameter for elasticity of intertemporal substitution to equal the inverse of the parameter for relative risk aversion. We specify a time-preference factor of 0.96, a common choice in the literature. In addition, we assume that the first investor supplies $e_{1, t} \in\{0.77,0.23\}$ units of labor, with $e_{1, t}$ following a first-order persistent Markov chain with a symmetric transition matrix: $E_{1,1}=E_{2,2}=0.75$. The second investor's supply is $e_{2, t}=1-e_{1, t}$. Note, this choice implies high fluctuations in wages; however, because we have only two investors rather than millions, we need the high volatility to generate a sufficiently strong risk-sharing motive for trade.

We then choose the remaining 10 parameters of the model, discussed in detail below, to closely match financial market and business cycle moments. The results are shown in Table 2 along with their empirical counterparts reported by Guvenen (2009). The risk-free rate as well as its volatility, which are $2.31 \%$ and $4.89 \%$ in the model with disagreement, are close to their empirical counterparts of $1.94 \%$ and $5.44 \%$. For the equity market, note that in reality most firms use debt to finance their assets. Accordingly, instead of reporting moments for the consumption claim, we report moments for levered equity, using a leverage factor of 1.75, as in Abel (1999), resulting in an equity premium of $6.97 \%$, slightly higher than the $6.17 \%$ in the data, and a volatility that is lower than that observed empirically (17.19\% vs. $19.30 \%)$. Finally, the model's log price-dividend ratio (3.06) fits very well the data (3.10), but with a volatility that is lower than that in the data $(19.6 \%$ vs. $26.3 \%)$.

While the mean long-run growth rate of $0.91 \%$ is lower than the growth rate of $1.60 \%$ typically used in the real-business-cycle literature, the volatility of output $(3.93 \%)$ matches the data $(3.78 \%)$ fairly well. Similarly, the investment-growth volatility is

\footnotetext{
${ }^{16} \mathrm{~A}$ detailed description of the stationarity distributions is available in the online appendix.
} 
matched reasonably well, with a volatility, normalized by the volatility of output, of 2.04 in the model compared to 2.39 in the data. In contrast, the model's aggregate consumption volatility, normalized by output volatility, is quite a bit higher than empirically observed (0.71 vs. 0.40$)$. The model shares this problem with a large set of macroeconomic models, such as Danthine and Donaldson (2002) and Guvenen (2009).

The parameters underlying this calibration are the following. A relative risk aversion of 8.5, lying within the range of 3 to 10 often employed in the literature and an elasticity of substitution of $1 / 8.5$. The wage share $(1-\alpha)$ is equal to 0.50 , which is in line with research by the U.S. Bureau of Economic Analysis that puts the share of employees compensation in the range of 0.50 to 0.60 . The rate of depreciation is 0.045 , slightly below the usual rate of 0.08 , and the capital adjustment cost parameter is 7.25. The mean of productivity $\bar{Z}$ is 0.325 with mean growth rates of $\bar{u}=0.041=-\bar{d}$ and meanreversion parameter $\nu=4 / 6$. The parameters of the Hidden Markov model, describing aggregate uncertainty, are given by: $A_{1,1}=A_{2,2}=0.90$, making the hidden states quite persistent; and $p=0.80$, implying a moderate probabilistic relation between the hidden states and observed productivity growth. This implies that productivity growth is quite persistent, consistent with empirical research that finds a high auto-correlation of the Solow residuals. Finally, the parameter governing the degree of disagreement between the two agents is $w=0.60$. This results in an average cross-agent dispersion of their output growth forecasts of $0.59 \%$, comparable to the findings of Andrade, Crump, Eusepi, and Moench (2014) and Paloviita and Viren (2012), who document a cross-sectional dispersion of forecasts of about $0.60 \%$ at the one-year horizon.

\subsection{Effects of Disagreement}

We now study the impact of the investors' disagreement on financial markets and the real economy. As a comparison, the last column of Table 2 shows also the results for an economy without disagreement $(w=0)$ in which both agents always agree on the expected future growth rate. 
As shown by Dumas, Kurshev, and Uppal (2009) for an exchange economy, the investors' fluctuating beliefs add new sources of risk. Specifically, the investors' beliefs are described by a stochastic process with stochastic volatility. As a reaction to these additional sources of risk, investors exhibit a precautionary-savings motive, leading to a considerably lower interest rate in the economy with disagreement: $(2.31 \%$ vs. to $3.36 \%)$. With this comes an increase in interest-rate volatility from $2.30 \%$ to $4.89 \%$.

Due to the stock's exposure to these additional sources of risk, its volatility increases from $13.29 \%$ in the economy without disagreement to $17.19 \%$ in the presence of disagreement, a relative increase of about $30 \%$. The equity risk premium itself increases, in tango with the stock's volatility, from $4.50 \%$ to $6.97 \%$, a relative increase of more than $50 \%$. These results imply an increase in the expected stock return, i.e., the firm's cost of capital, as well as an increase in the Sharpe ratio. These changes go along with very strong increases in the per annum turnover of the bond, normalized by capital (because it is homogenous in capital), from 0.013 to 0.203 shares - a fifteen-fold increase, and of the stock, from 0.027 to 0.139 shares - a five-fold increase. This indicates that the two financial assets are used to implement speculative trading strategies resulting from the disagreement, which then has a direct effect on the prices and returns of the two assets. Note that for speculation the bond plays a very important role; this will have an important bearing in interpreting the effects of different regulatory measures.

Focusing on the real side of the economy, we find that the higher cost of capital in the financial market directly translates into a lower rate of investment, i.e., while in the economy without disagreement $23.8 \%$ of output is reinvested, this rate drops to $22.7 \%$ in the model with disagreement. As the endogenous growth rate of the economy is driven by the firm's capital accumulation, this reduction in real investment implies a long-run rate of output growth that is 17 basis points lower per year, or, equivalently, about $15 \%$ lower in relative terms. Similarly, the higher volatility of the stock return, leads to a relative increase of almost $40 \%$ for the volatility of investment growth. 
Finally, we also study welfare. With heterogeneous beliefs and an incomplete market, welfare could be measured in many ways. At one extreme, one could measure welfare under the objective probability measure (sometimes called "ex post welfare"). But this would require that the regulator, in setting his policy, has extraordinary information abilities (to know the hidden state) not available even to fully rational human beings. Since the goal of the regulator is to mitigate the risk arising from disagreement while doing as little damage as possible to the real economy, it is logical to assume that he is himself aware that the public signal is noise. Otherwise, he would have no raison d'être. It follows from this observation that welfare should be calculated under the measure of the econometrician who has access to no more information than ordinary humans. He processes the information everyone has, but in a correct, Bayesian manner. That is, we evaluate the investors' welfare under the probability measure of an econometrician who uses the true observation matrix $\mathcal{O}$ to infer the probabilities for the hidden states of the economy. Our measure of welfare is an ex ante one, as is suitable for a regulator whose intervention can only have effects in the future. In line with this principle, we measure welfare per unit of capital stock. Ex post, the various regulatory measures will produce different probability distributions for the level of capital stock that is achieved. But ex ante, the economy as a whole, and the regulator in particular, have at their disposal a given amount of physical capital for which the best use is to be found. That is why we measure welfare ex ante per unit of available capital stock.

Under our measure of welfare, Table 2 documents that the welfare of investors in the presence of disagreement is considerably lower than in the economy without disagreement, by about $4 \%$ in relative terms, which is equivalent to a reduction of the same magnitude in initial capital and output. ${ }^{17}$ The reduction is quite sizable; for example, Barro (2009, Table 3) documents losses of $1.65 \%$ in initial output for introducing 'normal' macroeconomic uncertainty, though for a lower risk aversion of 4 .

\footnotetext{
${ }^{17}$ Obviously, in the economy without disagreement, welfare under the investors' subjective beliefs coincides with the welfare under the econometrician's measure because both use the same observation matrix $\mathcal{O}$.
} 
One could also consider the continuum of subjective welfare measures proposed by Blume, Cogley, Easley, Sargent, and Tsyrennikov (2015) and Heyerdahl-Larsen and Walden (2014); specifically, they suggest evaluating welfare under convex combinations of the individual investors' beliefs. Each investors' welfare using just their own subjective measure, i.e., the case in which the weight assigned to the other agent's beliefs is zero, is higher in the economy with disagreement - see the last row of Table 2. This is because investors falsely believe that they can exploit their counterpart's mistakes. However, our computations show that as soon as the minimum weight assigned to either investor's beliefs exceeds $5 \%$, then welfare in the economy with disagreement is lower compared to that without disagreement.

\subsection{Benefits of Risk-Sharing}

We now briefly describe the benefits that arise from the risk-sharing between investors. For this, we compare the economy in the absence of disagreement, i.e., an economy in which the only motive to trade stems from sharing labor-income risk, to economies which are also free of disagreement but in which trading in the bond and/or trading in the stock is prohibited, so that investors cannot change their initial holdings in the asset.

Prohibiting trading in both financial assets leads to tremendous welfare losses, because this increases the investors' consumption growth volatility considerably, as they cannot share their labor-income risk and have to consume exactly their wages and share of dividends. This increase in individual consumption volatilities creates a demand for precautionary savings. As trading in the financial assets is prohibited, the investors' only means to save are by increasing investment in the firm, so output in the restricted economy grows at a rate that is 140 basis points higher $(2.48 \%$ vs. $1.08 \%)$. However, this higher growth rate is dominated by the increase in consumption volatility, leading to welfare losses.

Limiting trading in a single market - either the bond or the stock — has substantially smaller effects. For example, prohibiting trading in the bond market leads to a reduction 
in welfare of only $0.08 \%$ (in relative terms). All other quantities are also virtually unchanged. Prohibiting trading in the stock market has stronger effects, leading to welfare losses of about $0.79 \%$ because of investors' limited ability to share labor-income risk.

In summary, while the bond seems to play only a minor role in optimal risk-sharing, the stock market is essential for risk sharing. The above analysis suggests that regulation that targets borrowing might be successful, because it does not harm risk-sharing but can potentially mitigate the negative effects of speculation.

\subsection{Effective Channels of Regulatory Measures}

Each of the regulatory measures that we study is intended to influence the economy through a particular channel. In order to appreciate the potential restrictiveness of each of these measures, and the way the severity of each constraint depends on the disagreement between investors, we plot in Figure 1 the distribution of stock holdings, borrowing and stock turnover before any regulation is imposed, for the economies with disagreement (left-hand column) and without disagreement (right-hand column).

We observe from the first row of Figure 1 that the density of the stock holdings of Investor 1 has a slightly wider support in the case of the model with disagreement compared to the model without disagreement, and that the probability mass for negative stock holdings is generally higher for the same holding threshold in the model with disagreement. Consequently, a constraint on stock-portfolio holdings will be more severe and will bind at a lower constraint level in the model with disagreement.

In the second row of Figure 1, we display the distribution of borrowing (relative to output). Comparing the left-hand side plot for the economy with disagreement to the plot on the right for economy without disagreement, we see that the effect of disagreement is larger on borrowing than on investment in the stock. The third row of Figure 1 shows a similar result for stock turnover, which is much greater in the presence of disagreement. 
We also depict, in the first row of Figure 2, the dynamics of the first investor's stock (left-hand plot) and bond (right-hand plot) holdings in the base-case economy without any financial regulations for fifteen years of a sample path. The solid lines, showing the holdings for the economy in the absence of disagreement, are relatively smooth, with the investor trading frequently but in small amounts. In contrast, in the presence of disagreement, the investor trades substantially more in the stock market (dashed line), as he reacts to the public signal. Importantly, to finance this additional trading in the stock, the investor relies heavily on borrowing because, compared to the economy without disagreement, his labor income is basically unchanged and so the only source of funding the additional trading in the stock is via additional trading in the bond (dashed line in right-hand plot). The trading in the stock and bond is also more erratic because of the transitory nature of the signal.

\section{Analysis of Regulatory Measures}

In this section, we examine closely the changes that occur when we apply a particular regulatory measure to our calibrated economy in Section 4. Specifically, we study the way the introduction of (i) portfolio (short-sale) constraints, (ii) borrowing (leverage) constraints, or (iii) Tobin tax on stock transactions, influences various financial and macroeconomic quantities, including welfare. To understand and illustrate the effects of the regulatory measure on optimal risk-sharing we also consider the economy, in which agents always agree on expected future growth, i.e., where the degree of disagreement is set to $w=0$, so that all trading is motivated by risk-sharing rather than speculation.

\subsection{Stock-Portfolio Constraints}

In this section, we study the effect of a regulatory measure that constrains the stockportfolio positions of investors. Typically, this constraint is used to restrict short-selling, which in equation (11) corresponds to setting $\rho=0$. In Table 2 , we have already reported the levels of various financial and macroeconomic variables in the presence of disagree- 
ment. In Figure 3 we plot the changes in these variables relative to the case without the regulatory measure for values of $\rho$ ranging from -0.50 (which limits shorting to half a share of stock) to 0.25 (which restricts investors to be long one quarter of a share). ${ }^{18}$

The direct impact of this constraint can be seen in Plot (e), where the stock turnover decreases with $\rho$. For example, when short-selling is prohibited $(\rho=0)$, stock turnover declines by about $8 \%$. Because the bond is used to finance trading in the stock, the decline in stock turnover is accompanied by a decline in bond turnover, as shown in Plot (d), whereas for the model without disagreement, when $\rho>0$ trading the bond is a substitute for trading the stock, and hence, bond turnover might increase.

The stock-portfolio constraint, by limiting risk-sharing, makes investors' consumption growth more volatile (not shown). This leads to an increase in investors' desire for precautionary savings, leading to a reduction in the interest rate, shown in Plot (a). In addition, because both financial assets are in limited supply, and in equilibrium both investors cannot increase their holdings in the financial assets, investors save by investment more physical capital in the firm, which increases the endogenous output growth rate $($ Plot $(\mathrm{g}))$. The increase in consumption volatility increases the equity premiumPlot (b) - and stock-return volatility-Plot (c).

As one would expect, the welfare implications of introducing the portfolio constraint are negative for the economy without disagreement (Plot $(\mathrm{h})$ ), as the constraint harms risk sharing. But, even in the economy with disagreement, the introduction of the constraint leads to welfare losses. The reason for this is that the stock holdings in the presence of the constraint deviate substantially from the optimal holdings causing the investor to consume suboptimal amounts, which leads to welfare losses. This is illustrated in the second row of Figure 2: the investor holds substantially more of the stock (thick dotted line) relative to the holdings in the economy without disagreement (solid line) because of the floor imposed by the portfolio constraint. In addition, the constraint can only partially restrict speculative trading, because investors' stock holdings can still change

\footnotetext{
${ }^{18}$ The online appendix also contains a figure in which, instead of changes, we plot the levels of these variables for different values of $\rho$.
} 
frequently and by large amounts, as illustrated in the second row of Figure 2. Thus, the welfare gains from limiting speculation are rather small, while the welfare losses from the restricted risk-sharing are large. On balance, this leads to the welfare losses shown in Plot (h) for the economy with disagreement. These results are similar to the empirical findings of Beber and Pagano (2013) and the views of at least some regulators: For instance, Christopher Cox, SEC Chairman, on 31 December 2008 states that: "The costs (of the short-selling ban on financial assets) appear to outweigh the benefits."

\subsection{Borrowing Constraints}

We now study the effects of a regulatory measure that constrains borrowing, measured relative to total output, and thereby limits investors' ability to take on leverage. Figure 4 shows how various financial and macroeconomic variables change as one reduces the amount of leverage possible, that is, as the borrowing constraint becomes more stringent.

As in the case of the constraint on stock-portfolio positions, the direct impact of the limit on borrowing is to reduce bond and stock turnovers, as shown in Plots (d) and (e) of Figure 4, respectively. And, just as in the case for the stock-portfolio constraint, the constraint on borrowing, by limiting risk-sharing, makes investors' consumption growth more volatile (not shown). This increases investors' precautionary-savings motive, leading to a reduction in the interest rate-Plot (a) and also to a higher output growth rate (Plot (g)) The increase in consumption volatility increases also the equity premiumPlot (b) - and stock-return volatility-Plot (c). All these effects are more striking in the economy with disagreement, where trading is driven also by speculation and not just by the desire to share labor-income risk.

In contrast to the case of regulating stock-portfolio positions, limiting borrowing has a positive welfare effect in the economy with disagreement, (Plot $(\mathrm{h})$ ). The intuition behind this result is as follows: As discussed in Section 4.3 and confirmed by the dashed graph in Figure $4(\mathrm{~h})$, limiting borrowing in the economy without disagreement has only a small effect on risk sharing, and hence, leads to minuscule welfare losses. In contrast, in the 
economy with disagreement, introducing a borrowing (leverage) constraint substantially impairs the investors' speculative activities, because to implement speculative trades they need access to the bond market. This is illustrated in the third row of Figure 2, which shows that, because the investor's borrowing is constrained, he can trade only small amounts in the stock market in reaction to the signal. Thus, the holdings (dotted line) are very close to the holdings in the economy without disagreement (solid line), and do not show the erratic behavior associated with trading on disagreement. The welfare gains from imposing limits on borrowing substantially offsets the negative welfare effects from impaired risk sharing, and hence, lead to an improvement in welfare.

\subsection{Tobin Financial-Transactions Tax}

The Tobin financial-transactions tax that we study is imposed on trading of the stock, and thus, it has a substantial effect on stock turnover, as can be seen from Plot (e) in Figure 5. We now explain the different roles played by the bond. In the economy without disagreement, trading in the bond is a substitute for trading the stock, and hence, as the stock turnover decreases with the Tobin tax (Plot (e)), the turnover in the bond increases (dash-dotted line in Plot $(\mathrm{d})$ ). On the other hand, in the economy with disagreement, trading in the bond is used also to finance the trading in the stock; thus, on balance, the bond is a complementary asset; therefore, as the Tobin tax increases, the turnover of the bond and stock decrease together (dotted lines in Plots (d) and (e)).

As in the case for the stock-portfolio constraint, the Tobin tax worsens risk-sharing. Comparable to the other measures, this, in turn, increases investors' consumption growth volatilities which then strengthens their precautionary savings motive. Accordingly, we observe a reduction in the interest rate (Plot (a)), and a higher growth rate of output (Plot $(\mathrm{g})$ ), as investors use both, the investments into the bond and investments on the firm level, to save. The increase in consumption volatility also implies an increase in the equity premium (Plot (b)) and an increase in stock-return volatility (Plot (c)). 
Focusing on the welfare implications, we can see that, as expected, welfare is reduced in the economy without disagreement as the tax limits risk sharing. Interestingly, the introduction of the Tobin tax improves welfare in the economy with disagreement (Plot (h)), even though it applies to trades in the stock market which is essential for risk sharing. This positive effect on welfare can be attributed to the fact that the transaction tax does not prevent investors from making frequent, but smooth adjustments to hedge their labor risk - it only makes those adjustment costly. Importantly, and in contrast to the portfolio constraint, the Tobin tax imposes no limits on stock positions, so the stock holdings in the economy with the transaction tax are relatively close to the optimal holdings in the economy without disagreement - even if those are relatively high or low. The smaller deviations from the optimal holdings in the absence of disagreement, can be seen when comparing the stock holdings (thick dotted line) shown in the last row of Figure 2 to the holdings for the case of the stock portfolio constraints - each relative to the optimal holdings in the absence of disagreement (solid line). Accordingly, the tax causes relatively small welfare losses by reducing risk sharing.

On the other hand, the Tobin tax substantially reduces speculative trading. Specifically, because the public signal that investors receive is not persistent, speculative trading, in the absence of trading costs, leads to frequent and big changes in stock holdings. However, in the presence of the tax these frequent and erratic changes are costly. In response to the Tobin tax, investors smooth their stock holdings, and thus, reduce their speculative trades - the last row of Figure 2 shows that the holdings in the presence of the tax (thick dotted line) are much smoother than in the unregulated economy with disagreement (dashed line). The reduction in speculative trades leads to welfare improvements.

\section{$6 \quad$ Robustness and Extensions of Results}

We now discuss how our conclusions are affected by changes in various model parameters. The results for the various robustness experiments we consider, and for comparison the results for our base-case model, are collected in Table 3. 
First, we report the case in which there is no disagreement (titled " $w=0 "$ ). In this case, the changes in welfare from shutting down one of the market are the same as for the base case. The first panel, which reports the change in results with respect to the economy without disagreement, is exactly this case itself, so financial and real quantities do not change. When evaluating the effects of introducing the stock constraint, we see that the results for the case without disagreement $(w=0)$ have the same sign as the results for the base case. Mostly, the magnitudes are smaller because the absence of disagreement reduces the need to trade stock and to borrow, because in the absence of disagreement there is no speculative trading. As one would expect, all three regulatory measures have a negative effect on welfare, because there is no speculative trading and so the measures only impair risk sharing.

Second, we consider the case of an economy where labor income is not risky, i.e., an economy in which both investors always receive half of the wages paid, which is reported in the column titled " $e_{1, \cdot}=0.5$ ". In this case, there is no risk to be shared, so shutting down either the stock or the bonds market in the economy without disagreement causes no welfare losses. The implications of introducing disagreement between investors in this setting (first panel) are qualitatively and quantitatively comparable to our base case. Focusing on the effects of financial regulation (the bottom three panels), one can see that all three measures have a positive effect on welfare, because they limit speculative trading without affecting risk sharing (which is not needed in the absence of risky labor income).

Third, we study an economy with a risk aversion of $\gamma=4$ instead of 8.5 in the base case. The results for this experiment are reported in the second-last column of Table 3, titled " $\gamma=4$ ". Because of the lower risk aversion, shutting down either the stock or the bonds market in the economy leads to welfare losses that are about a tenth of the losses in the base case. When we incorporate disagreement into this economy (first panel), the effects are qualitatively the same as in our base case, but we can see some quantitative differences. Importantly, we still observe a substantial loss in welfare. This can be explained by two opposing effects: because of their lower risk aversion, investors 
are better able to bear the additional risk created by disagreement, but at the same time investors are willing to take more risks (more extreme positions) in reaction to the signal they receive. While welfare losses in this setup are comparable to the base case, financial markets are less important for risk sharing, and therefore all three regulatory measures, by limiting speculation, improve welfare. The effects on the other variables are qualitatively the same as for the special case without risk sharing (in the column titled " $\left.e_{1, .}=0.5 "\right)$ that is discussed above.

Finally, we consider the case where the intertemporal elasticity of substitution is above one $(\psi=1.50$, instead of $\psi=1 / 8.5$ in the base case), i.e., investors have a preference for the early resolution of uncertainty. These results are reported in the last column of Table 3. We find that in the absence of disagreement, shutting down trading in either the stock or the bond leads to welfare losses that are smaller than those in our base case. Similarly, even with disagreement, we see from the first panel that the welfare losses are smaller than in the base case. All other quantities reported in the first panel change in the opposite direction to that for the base case. The reason is that with a preference for early resolution of uncertainty, investors react to changes in expectations of future growth by consuming more and investing less, increasing the interest rate and reducing the cost of capital, which leads to more investment by the firm and a higher growth rate. These results are in line with the findings of Heyerdahl-Larsen and Walden (2014) and Baker, Hollifield, and Osambela (2016) ${ }^{19}$ Focusing on the regulatory measures (bottom three panels), we can see that again, all three measures lead to welfare improvements because financial markets in general, and the stock market in particular, are less important for risk sharing. Accordingly, the other quantities change similarly to the two cases discussed above, in the columns titled " $e_{1, .}=0.5$ " and " $\gamma=4$ ", where the desire for risk sharing is smaller than that in the base case.

\footnotetext{
${ }^{19} \mathrm{Li}$ and Loewenstein (2015) find similar results for CRRA utility with a risk aversion below one, i.e., intertemporal elasticity of substitution above one.
} 


\section{Conclusion}

We have undertaken a general-equilibrium analysis of a production economy with investors who are uncertain about the current state of the economy and disagree in a time-varying way about its expected growth rate. Trading in financial markets allows investors to share labor-income risks. But, financial markets also provide an arena for speculative trading amongst investors who disagree. This speculative trading increases volatility of bond and stock returns and also the volatility of investment growth, increases the equity risk premium, and reduces welfare.

We analyze three regulatory measures intended to reduce the harmful effects of speculative trading. Our analysis shows that all three measures have similar effects on financial and macroeconomic variables, such as stock and bond turnovers, the risk-free rate, the equity risk premium, stock-return volatility, capital investment, and output growth. However, the regulatory measures have very different implications for welfare. Specifically, only measures that limit speculative activities without impairing risk-sharing substantially, improve welfare. In our calibrated model, this is the case for the borrowing constraint and the transaction tax. In contrast, the constraint on stock positions (a special case of which is a ban on short sales) reduces welfare because, even though it reduces speculation, it hurts risk sharing. Thus, to effectively regulate financial markets, it is important to identify the roles played by different markets in risk sharing and speculative activities of investors. Also, it is important to recognize that even though financial regulation may increase volatility in financial and real markets, this increase in volatility could still be associated with an improvement in welfare. 


\section{References}

Abel, A. B., 1999, "Risk Premia and Term Premia in General Equilibrium," Journal of Monetary Economics, 43, 3-33.

Alchian, A., 1950, "Uncertainty, Evolution and Economic Theory," Journal of Political Economy, 58(3), 211-221.

Andrade, P., R. K. Crump, S. Eusepi, and E. Moench, 2014, "Fundamental Disagreement," Federal Reserve Bank of New York Staff Report No. 655.

Anthony, J., M. Bijlsma, A. Elbourne, M. Lever, and G. Zwart, 2012, "Financial Transaction Tax: Review and Assessment," CPB Discussion Paper 202.

Arif, S., and C. M. C. Lee, 2014, "Aggregate Investment and Investor Sentiment," Review of Financial Studies, 27(11), 3241-3279.

Armand, P., J. Benoist, and D. Orban, 2008, "Dynamic updates of the barrier parameter in primal-dual methods for nonlinear programming," Computational Optimization and Applications, 41, 1-25.

Ashcraft, A., N. Gârleanu, and L. H. Pedersen, 2010, "Two Monetary Tools: Interest Rates and Haircuts," NBER Macroeconomics Annual, 25, 143-180.

Baker, S. D., B. Hollifield, and E. Osambela, 2016, "Disagreement, speculation, and aggregate investment," Journal of Financial Economics, 119(1), 210 - 225.

Barberis, N., A. Shleifer, and R. Vishny, 1998, "A Model of Investor Sentiment," Journal of Financial Economics, 49(3), 307-343.

Barro, R. J., 2009, "Rare Disasters, Asset Prices, and Welfare Costs," American Economic Review, 99(1), 243-264.

Baum, L. E., T. Petrie, G. Soules, and N. Weiss, 1970, "A Maximization Technique Occurring in the Statistical Analysis of Probabilistic Functions of Markov Chains," Annals of Mathematical Statistics, 41(1), 164-171.

Beber, A., and M. Pagano, 2013, "Short-Selling Bans Around the World: Evidence from the 2007-09 Crisis," The Journal of Finance, 68(1), 343-381.

Blume, L. E., T. Cogley, D. A. Easley, T. J. Sargent, and V. Tsyrennikov, 2015, "A Case for Incomplete Markets," Institute for Advanced Studies Working Paper No. 313.

Brunnermeier, M. K., A. Simsek, and W. Xiong, 2014, "A Welfare Criterion for Models with Distorted Beliefs," The Quarterly Journal of Economics, 129(4), 1753-1797.

Buss, A., and B. Dumas, 2015, "Trading Fees and Slow-Moving Capital," Working Paper, INSEAD. 
Chabakauri, G., 2013a, "Asset Pricing with Heterogeneous Investors and Portfolio Constraints," Working Paper, London School of Economics.

— , 2013b, "Dynamic Equilibrium with Two Stocks, Heterogeneous Investors, and Portfolio Constraints," forthcoming in The Review of Financial Studies.

Coen-Pirani, D., 2005, "Margin Requirements and Equilibrium Asset Prices," Journal of Monetary Economics, 52(2), 449-475.

Crawford, A., C. Graham, and E. Bordeleau, 2009, "Regulatory Constraints on Leverage: The Canadian Experience," Financial system review, Bank of Canada.

Daniel, K., D. Hirshleifer, and A. Subrahmanyam, 1998, "Investor Psychology and Security Market Under- and Overreactions," The Journal of Finance, 53(6), 1839-1885.

Danthine, J.-P., and J. B. Donaldson, 2002, "Labour Relations and Asset Returns," The Review of Economic Studies, 69(1), 41-64.

Detemple, J. B., and S. Murthy, 1994, "Intertemporal Asset Pricing with Heterogeneous Beliefs," Journal of Economic Theory, 62, 294-320.

Dumas, B., A. Kurshev, and R. Uppal, 2009, "Equilibrium Portfolio Strategies in the Presence of Sentiment Risk and Excess Volatility," The Journal of Finance, 64(2), $579-629$.

Dumas, B., and A. Lyasoff, 2012, "Incomplete-Market Equilibria Solved Recursively on an Event Tree," The Journal of Finance, 67(5), 1897-1941.

Eichenbaum, M., 2010, "What Shortcomings in Macroeconomic Theory and Modelling have been Revealed by the Financial Crisis and how should they be Addressed in the Future?," Comments from an ECB panel,http://faculty.wcas.northwestern.edu/ yona/research.html.

Epstein, L. G., and S. Zin, 1989, "Substitution, Risk Aversion and the Temporal Behavior of Consumption and Asset Returns: A Theoretical Framework," Econometrica, 57, 937-969.

Fedyk, Y., C. Heyerdahl-Larsen, and J. Walden, 2013, "Market Selection and Welfare in a Multi-asset Economy," Review of Finance, 17(3), 1179-1237.

Friedman, M., 1953, Essays in Positive Economics. University of Chicago Press, Chicago, IL.

Geanakoplos, J., 2009, "The Leverage Cycle," in NBER Macroeconomic Annual, ed. by Acemoglu, D., K. Rogoff, and M. Woodford, vol. 24, pp. 1-65. University of Chicago Press.

Geanakoplos, J., and A. Fostel, 2008, "Collateral Restrictions and Liquidity UnderSupply: A Simple Model," Economic Theory, 35, 441-467. 
Guvenen, F., 2009, "A Parsimonious Macroeconomic Model for Asset Pricing," Econometrica, 77(6), 1711-1750.

Hansen, L. P., 2007, "Beliefs, Doubts and Learning: Valuing Macroeconomic Risk," American Economic Review, 97(2), 1-30.

— , 2010, "Calibration, Empirical Evidence, and Stochastic Equilibrium Models," Slides for presentation at Cambridge INET Conference.

Heyerdahl-Larsen, C., and J. Walden, 2014, "Efficiency and Distortions in a Production Economy with Heterogeneous Beliefs," Working Paper LBS.

Hong, H., and J. C. Stein, 1999, "A Unified Theory of Underreaction, Momentum Trading, and Overreaction in Asset Markets," The Journal of Finance, 54(6), 2143-2184.

Krishnamurthy, A., 2003, "Collateral Constraints and the Amplification Mechanism," Journal of Economic Theory, 111(2), 277-292.

Li, T., and M. Loewenstein, 2015, "Does Speculative Activity Have Real Effects?," Working paper, University of Maryland.

Loewenstein, M., and G. A. Willard, 2006, "The Limits of Investor Behavior," The Journal of Finance, 61(1), 231-258.

McCulloch, N., and G. Pacillo, 2011, "The Tobin Tax: A Review of the Evidence," Institute of Development Studies Research Report 68, University of Sussex.

Paloviita, M., and M. Viren, 2012, "Inflation and output growth uncertainty in individual survey expectations," Bank of Finland Research Discussion Papers 37.

Panageas, S., 2005, "The Neoclassical Theory of Investment in Speculative Markets," Working Paper, University of Pennsylvania.

Rabiner, L. R., 1989, "A Tutorial on Hidden Markov Models and Selected Applications in Speech Recognition," Proceedings of the IEEE, 77, 257-285.

Sargent, T. J., 2008, "Evolution and Intelligent Design," American Economic Review, $98(1), 5-37$.

Scheinkman, J. A., and W. Xiong, 2003, "Overconfidence and Speculative Bubbles," Journal of Political Economy, 111, 1183-1219.

Stiglitz, J. E., 2010, "An Agenda for Reforming Economic Theory," Slides for presentation at Cambridge INET Conference.

Weil, P., 1990, "Nonexpected Utility in Macroeconomics," Quarterly Journal of Economics, 105, 29-42. 
Table 1: Model Parameters

\begin{tabular}{lcc}
\hline \hline Variable & Description & Value \\
\hline & & \\
Production & & \\
Capital share in output & $\bar{Z}$ & 0.50 \\
Avg. productivity & $\bar{u}=-\bar{d}$ & 0.325 \\
Avg. productivity growth & $\nu$ & 0.641 \\
Mean-reversion productivity growth & $\delta$ & 0.045 \\
Depreciation & $\xi$ & 7.25 \\
Adjustment costs & & \\
& & \\
Investors & $\beta$ & 0.96 \\
Rate of time preference & $\gamma$ & 8.50 \\
Risk aversion & $\psi$ & $1 / \gamma$ \\
Elasticity of intertemporal substitution & $w$ & 0.60 \\
Degree of disagreement & $E_{1,1}=E_{2,2}$ & 0.75 \\
Persistence labor shocks & $e_{1, u}=e_{2, u}$ & 0.77 \\
High individual labor supply & $e_{1, d}=e_{2, d}$ & 0.23 \\
Low individual labor supply & & \\
& & \\
Uncertainty: Hidden Markov model & & \\
Persistence of hidden states & $A_{1,1}=A_{2,2}$ & 0.90 \\
Precision of productivity shocks & $p$ & 0.80 \\
Initial probability hidden state 1 & $\pi$ & 0.50 \\
& & \\
\hline \hline
\end{tabular}

In this table, we provide a summary of the model parameters, divided into three categories: the parameters for the production process; the parameters for the investors' preferences, their degree of disagreement, and their labor-income processes; and, the parameters of the Hidden Markov model describing the state of the economy. The values assigned to these parameters are described in detail in Section 2. 
Table 2: Financial and Business Cycle Statistics

\begin{tabular}{|c|c|c|c|c|}
\hline \multirow[b]{2}{*}{ Description } & \multirow[b]{2}{*}{ Variable } & \multirow[b]{2}{*}{ U.S. Data } & \multicolumn{2}{|c|}{ Disagreement } \\
\hline & & & Yes & No \\
\hline \multicolumn{5}{|l|}{ Financial markets } \\
\hline Interest rate & $r_{f}$ & $1.94 \%$ & $2.31 \%$ & $3.36 \%$ \\
\hline Interest rate volatility & $\sigma\left(r_{f}\right)$ & $5.44 \%$ & $4.89 \%$ & $2.30 \%$ \\
\hline Levered equity premium & $\mathbb{E}\left[R^{e p}\right]$ & $6.17 \%$ & $6.97 \%$ & $4.50 \%$ \\
\hline Levered stock return volatility & $\sigma(R)$ & $19.30 \%$ & $17.19 \%$ & $13.29 \%$ \\
\hline Log price-dividend ratio & $\log (S / D)$ & 3.10 & 3.06 & 3.11 \\
\hline Volatility price-dividend ratio & $\sigma(\log (S / D))$ & $26.30 \%$ & $19.60 \%$ & $13.40 \%$ \\
\hline \multicolumn{5}{|l|}{ Real economy } \\
\hline Output growth & $E[Y]$ & $1.60 \%$ & $0.91 \%$ & $1.08 \%$ \\
\hline Output growth volatility & $\sigma(Y)$ & $3.78 \%$ & $3.93 \%$ & $3.94 \%$ \\
\hline Norm. investment growth volatility & $\sigma(I) / \sigma(Y)$ & 2.39 & 2.04 & 1.46 \\
\hline Norm. consumption growth volatility & $\sigma(C) / \sigma(Y)$ & 0.40 & 0.71 & 0.87 \\
\hline \multicolumn{5}{|l|}{ Turnover } \\
\hline Bond market & & - & 0.203 & 0.013 \\
\hline Stock market & & - & 0.139 & 0.027 \\
\hline \multicolumn{5}{|l|}{ Welfare (certainty consumption) } \\
\hline Econometrician's measure & & - & 0.1238 & 0.1289 \\
\hline Subjective measure & & - & 0.1312 & 0.1288 \\
\hline
\end{tabular}

In this table, we provide a summary of various moments in the data and in the calibrated model for financial markets and macroeconomic variables. The calibration of the model is described in Section 4.1, and the moments for the data are taken from Guvenen (2009). Note that normalized investment-growth volatility is the ratio of investment growth volatility to output volatility and normalized consumption volatility is the ratio of consumption volatility to output volatility. All model moments are computed using data from the last 50 years of the 25,000 simulations when the economy has reached its steady-state distribution. 
Table 3: Robustness Analysis (measured in changes)

\begin{tabular}{lccccc}
\hline \hline & Base Case & $w=0$ & $e_{1, \cdot}=0.5$ & $\gamma=4$ & $\psi=1.5$ \\
\hline $\begin{array}{l}\text { Changes due to disagreement } \\
\text { (w.r.t. model without disagreement) }\end{array}$ & & & & & \\
Interest rate & $-31.22 \%$ & $0.00 \%$ & $-20.29 \%$ & $-9.81 \%$ & $0.96 \%$ \\
Levered equity premium & $54.87 \%$ & $0.00 \%$ & $57.74 \%$ & $55.63 \%$ & $-7.45 \%$ \\
Levered stock return volatility & $29.39 \%$ & $0.00 \%$ & $26.83 \%$ & $23.21 \%$ & $-5.97 \%$ \\
Capital investment (\%output) & $-4.67 \%$ & $0.00 \%$ & $-4.30 \%$ & $-3.01 \%$ & $0.33 \%$ \\
Output growth & $-16.20 \%$ & $0.00 \%$ & $-31.99 \%$ & $-14.64 \%$ & $0.78 \%$ \\
Welfare & $-3.97 \%$ & $0.00 \%$ & $-3.94 \%$ & $-4.02 \%$ & $-1.38 \%$
\end{tabular}

Changes due to stock portfolio constraint $\rho=0.25$

(w.r.t. model with disagreement, but no regulation)

$\begin{array}{lccccc}\text { Interest rate } & -9.36 \% & -1.87 \% & 1.25 \% & 0.94 \% & -0.47 \% \\ \text { Levered equity premium } & 1.61 \% & 0.95 \% & -4.53 \% & -15.67 \% & -12.05 \% \\ \text { Levered stock return volatility } & 4.56 \% & 2.45 \% & 0.78 \% & 2.50 \% & 0.46 \% \\ \text { Capital investment (\%output) } & 3.98 \% & 1.46 \% & 0.55 \% & 2.30 \% & 1.65 \% \\ \text { Output growth } & 14.66 \% & 4.48 \% & 5.49 \% & 12.28 \% & 3.85 \% \\ \text { Welfare } & -1.34 \% & -0.38 \% & 0.70 \% & 1.84 \% & 0.88 \%\end{array}$

Changes due to borrowing constraint $\kappa=-0.3$

(w.r.t. model with disagreement, but no regulation)

$\begin{array}{lccccc}\text { Interest rate } & -33.74 \% & -0.04 \% & -20.93 \% & -17.65 \% & -7.58 \% \\ \text { Levered equity premium } & 18.93 \% & 0.35 \% & 20.55 \% & 37.40 \% & 29.68 \% \\ \text { Levered stock return volatility } & 1.75 \% & 0.18 \% & 1.09 \% & 1.64 \% & -0.55 \% \\ \text { Capital investment (\%output) } & 1.76 \% & 0.18 \% & 1.33 \% & 1.85 \% & -0.44 \% \\ \text { Output growth } & 6.51 \% & 0.54 \% & 13.05 \% & 9.77 \% & -1.04 \% \\ \text { Welfare } & 1.62 \% & -0.02 \% & 2.02 \% & 3.49 \% & 1.38 \%\end{array}$

Changes due to transaction tax $\tau=0.5 \%$

(w.r.t. model with disagreement, but no regulation)

$\begin{array}{lccccc}\text { Interest rate } & -6.33 \% & -8.09 \% & -0.86 \% & -0.19 \% & -1.46 \% \\ \text { Levered equity premium } & 2.78 \% & 0.60 \% & 1.94 \% & 1.24 \% & 2.76 \% \\ \text { Levered stock return volatility } & 2.19 \% & 8.68 \% & 0.12 \% & -0.24 \% & -0.37 \% \\ \text { Capital investment (\%output) } & 2.63 \% & 4.48 \% & 1.18 \% & 1.74 \% & 1.62 \% \\ \text { Output growth } & 9.69 \% & 13.42 \% & 11.65 \% & 9.20 \% & 3.77 \% \\ \text { Welfare } & 1.03 \% & -1.41 \% & 1.23 \% & 1.62 \% & 1.03 \%\end{array}$

In this table, we provide a summary of the effects in our model as we change various parameters. The column titled "Base Case" shows the results for the main model discussed in the text. The other columns present the results for setups in which there is no disagreement " $w=0$ ", no labor income risk " $e_{1,}=0.5$ ", investors have a risk aversion $\gamma=4$ instead of the 8.5 in the base case, and investors have Epstein-Zin-Weil preferences with a preference for early resolution of uncertainty $(\psi=1.5)$ instead of $\psi=1 / 8.5$ in the base case. The first panel presents the changes arising from disagreement, relative to the economy without disagreement and without regulations. The remaining three panels show the impact that the three regulatory measures have, relative to the economy with disagreement but without regulations. 
Figure 1: Histograms

With Disagreement
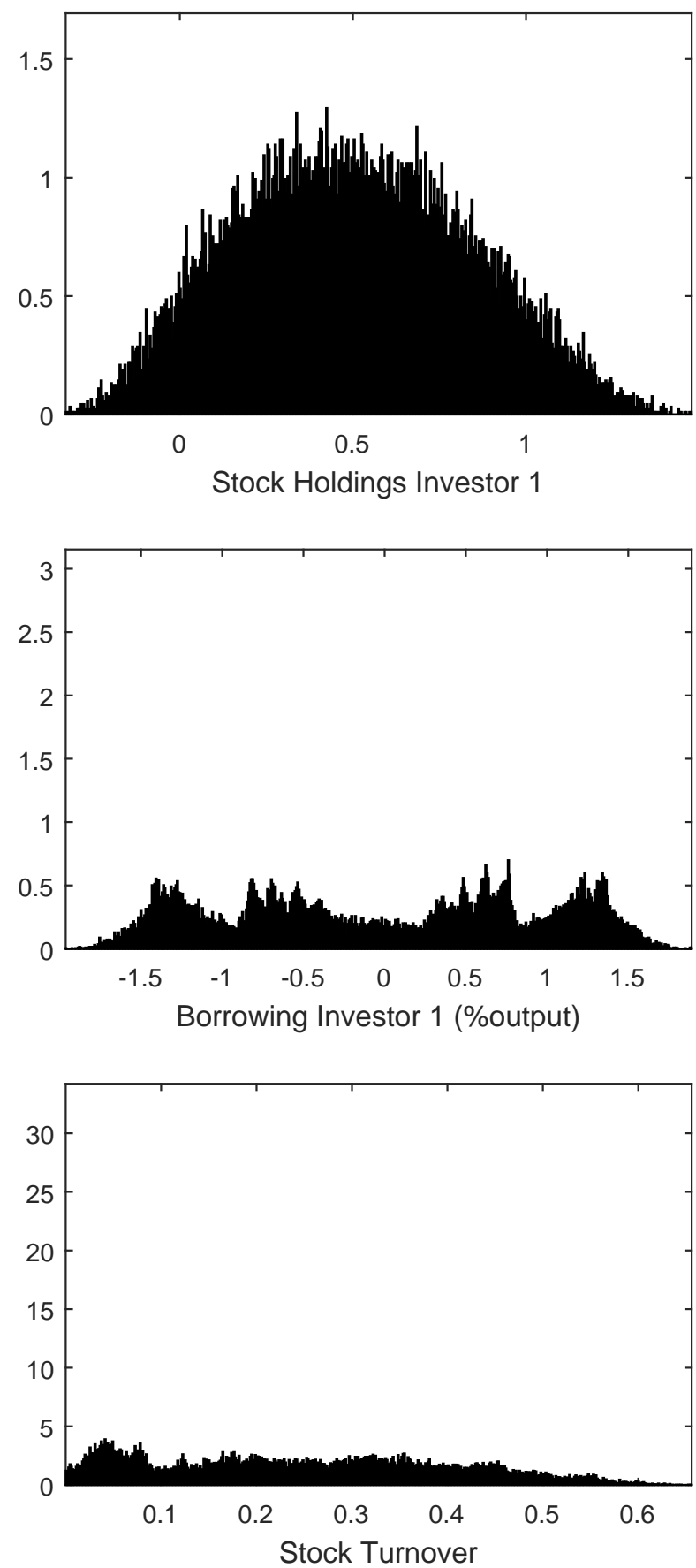

Without Disagreement
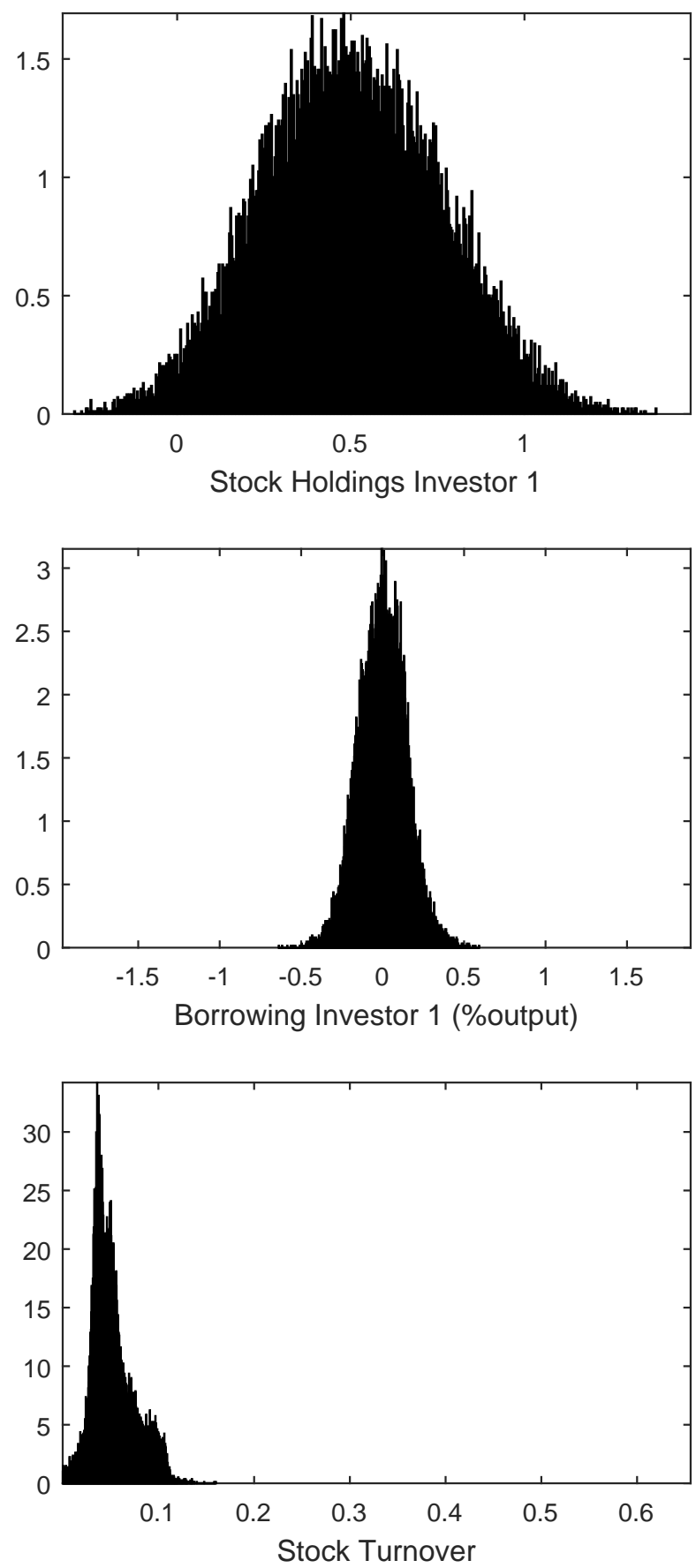

This figure depicts the simulated distribution of three variables: the first row shows the stock holdings of Investor 1, the second row shows the first investor's borrowing as a share of total output, and the third row shows stock turnover. The figures on the left-hand side column are for the economy "with disagreement" in which investors disagree about the state of the economy, and the figures in the right-hand side column are for the economy "without disagreement." The histogram shows the quantities at the end of the horizon of a 200 year simulation with 25,000 paths. The histograms are normalized to integrate to one. 
Figure 2: Simulated path of the economy

Basic Model
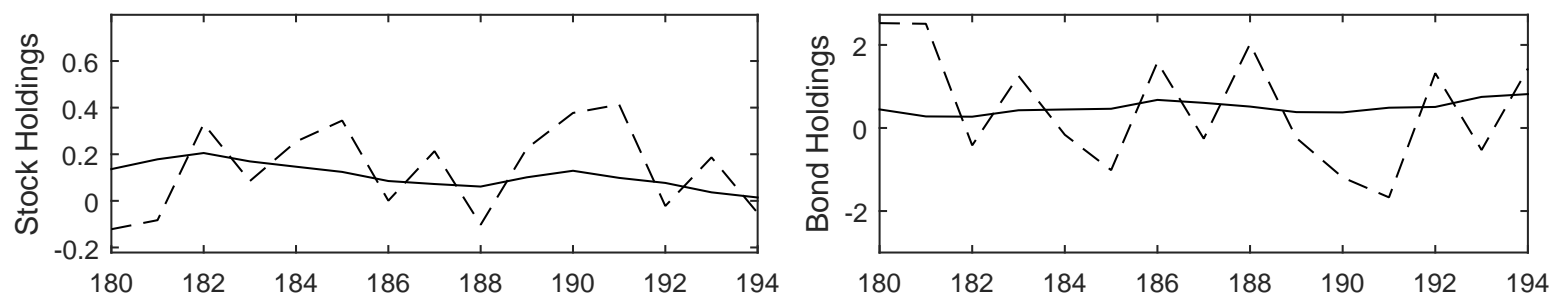

Stock portfolio constraint $\rho=0.25$
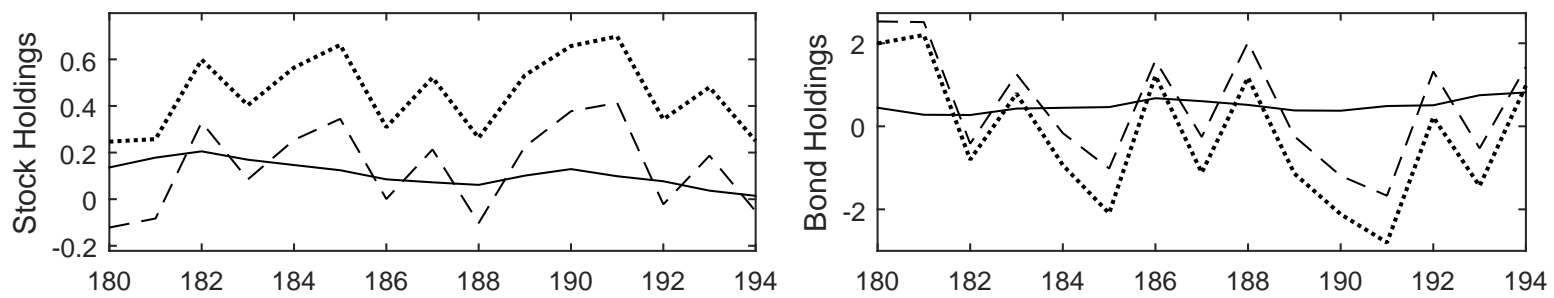

Borrowing constraint $\kappa=0.1$
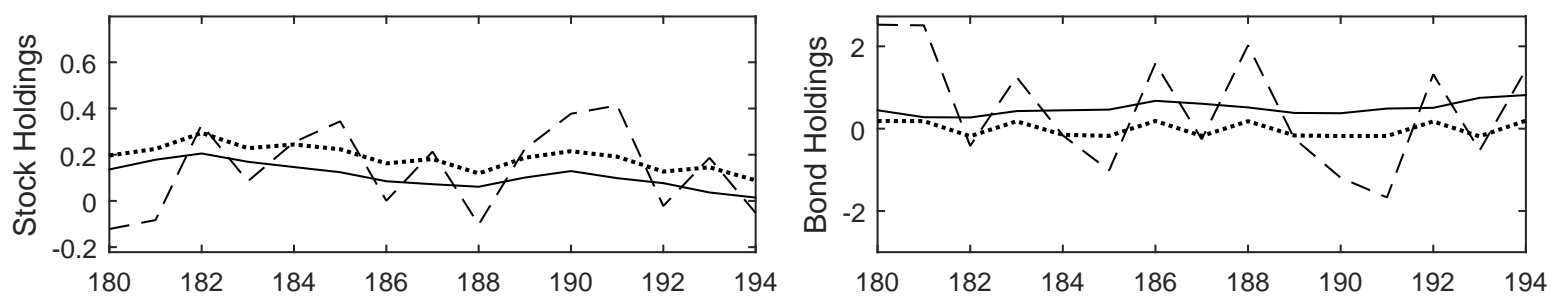

Transaction $\operatorname{tax} \tau=1 \%$
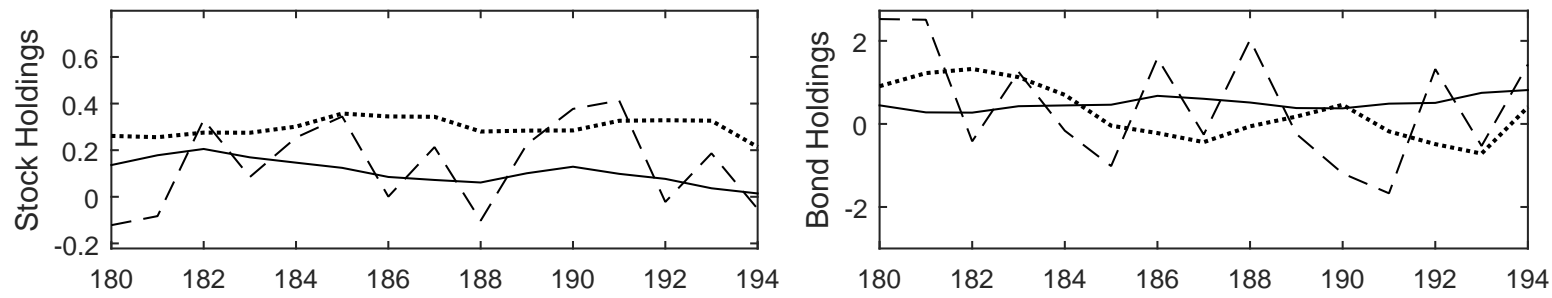

Without disagreement --- With disagreement $. . . \cdots \cdots . .$. With disagreement and regulation

The figure shows a simulated path of the economy for years 180 to 194 . The first row depicts the evolution of the first investor's stock holdings (number of shares) and bond holdings (\% output) in the basic (unregulated) economy in the absence (solid line) as well as in the presence of disagreement (dashed line); the second to fourth rows show the evolution of the holdings in the presence of different regulatory measures (thick dotted line) and, for comparison, also their evolution in the absence of regulation. 
Figure 3: Effect of constraint on stock portfolio (measured in changes)

(a) Interest rate

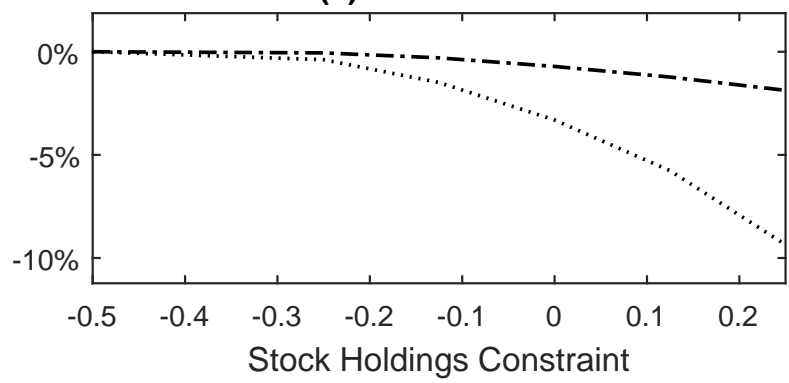

(c) Levered stock return volatility

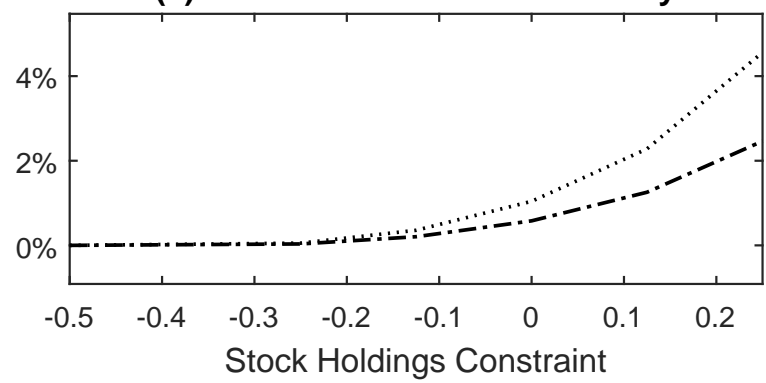

(e) Stock turnover

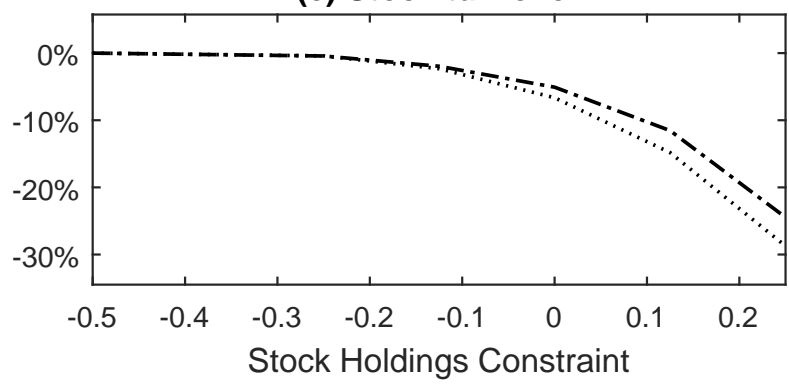

(g) Output growth

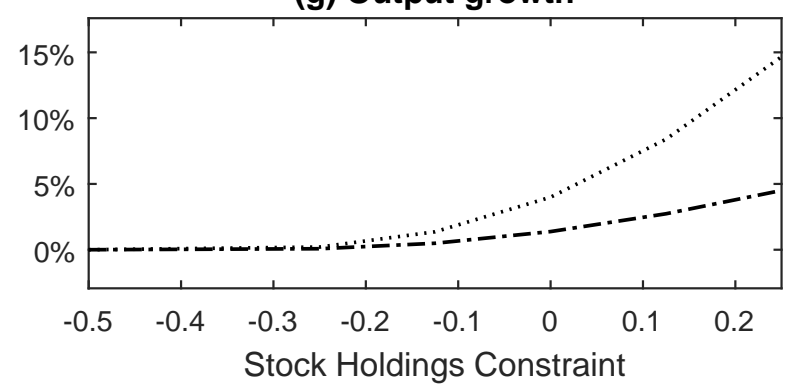

(b) Levered equity premium

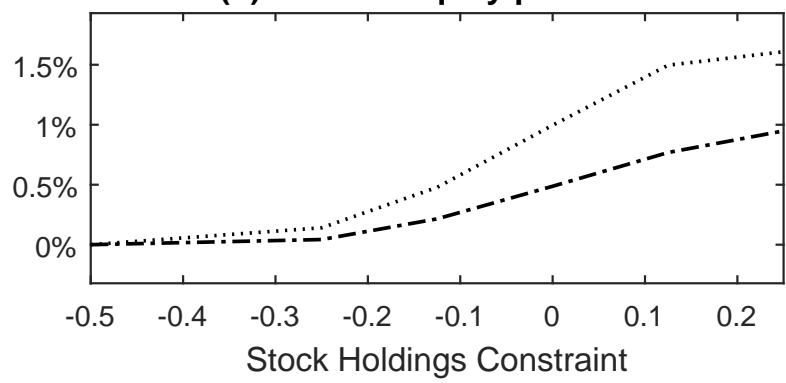

(d) Bond turnover

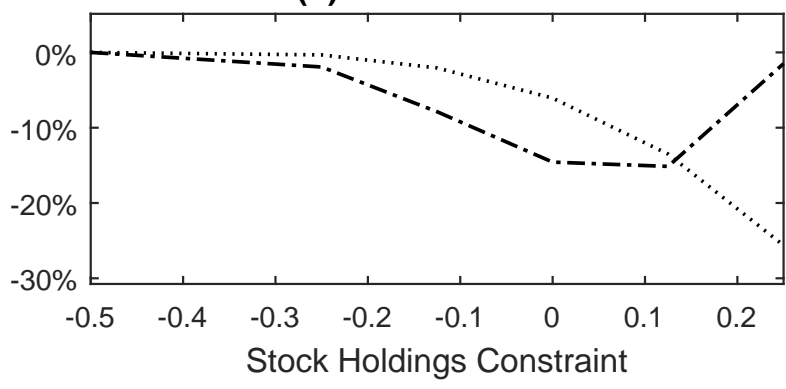

(f) Capital investment (\%output)

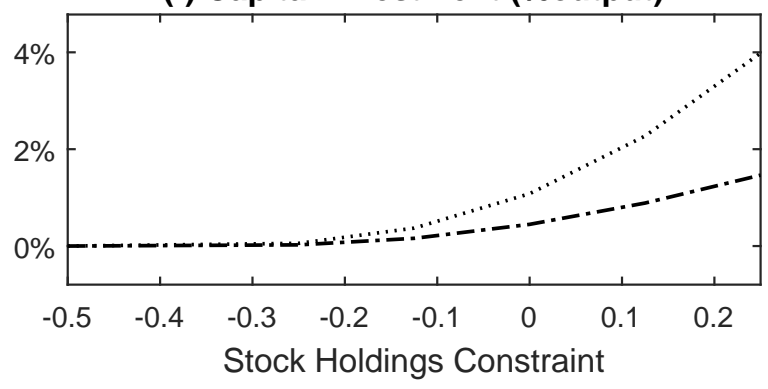

(h) Welfare

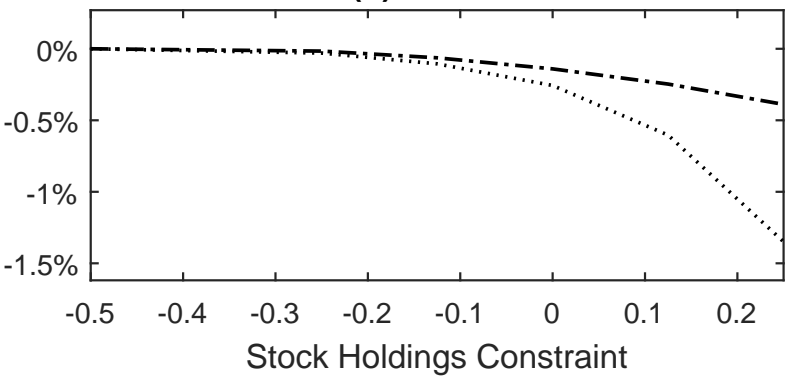

With Disagreement ---.-Without Disagreement

The eight panels in this figure show how constraining stock-portfolio positions changes various financial and macroeconomic quantities. The dotted line is for the economy with disagreement between the two classes of investors and the dash-dotted line is for the economy without disagreement. 
Figure 4: Effect of constraint on borrowing (measured in changes)

(a) Interest rate

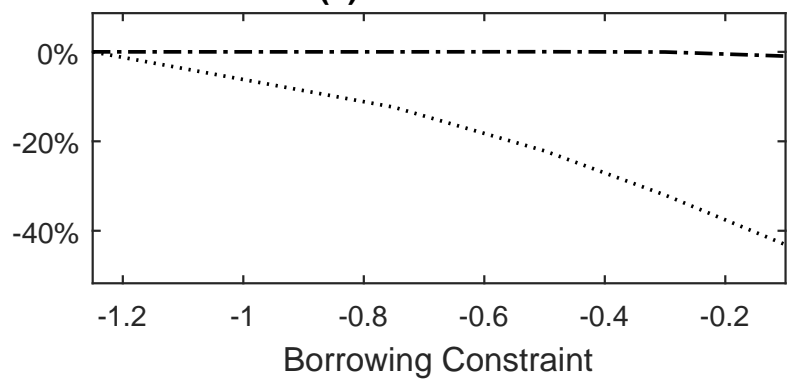

(c) Levered stock return volatility

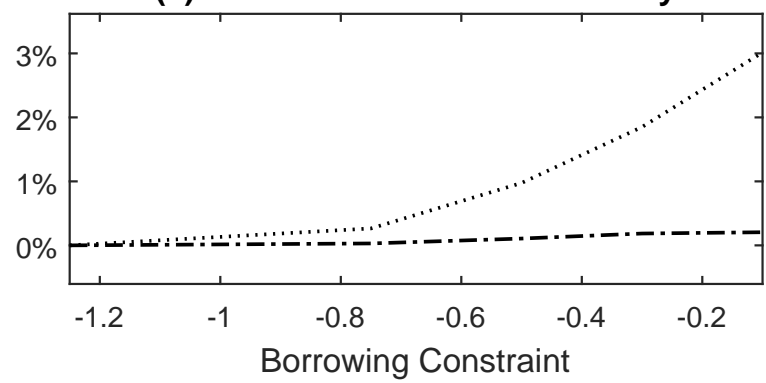

(e) Stock turnover

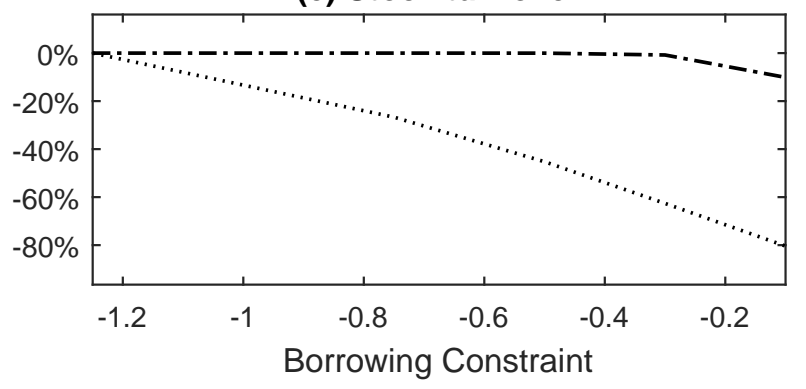

(g) Output growth

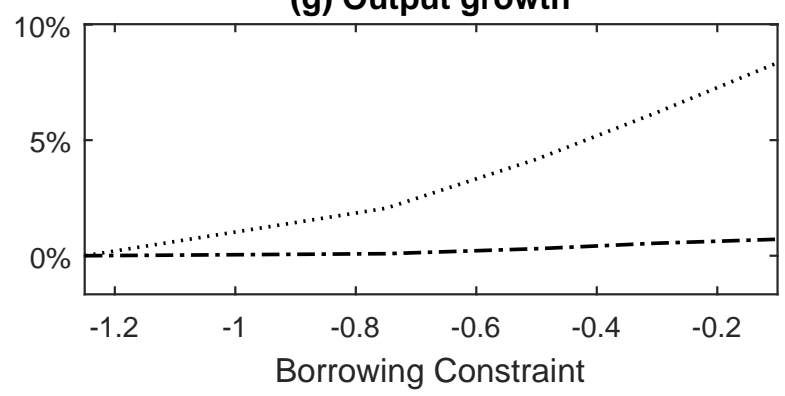

(b) Levered equity premium

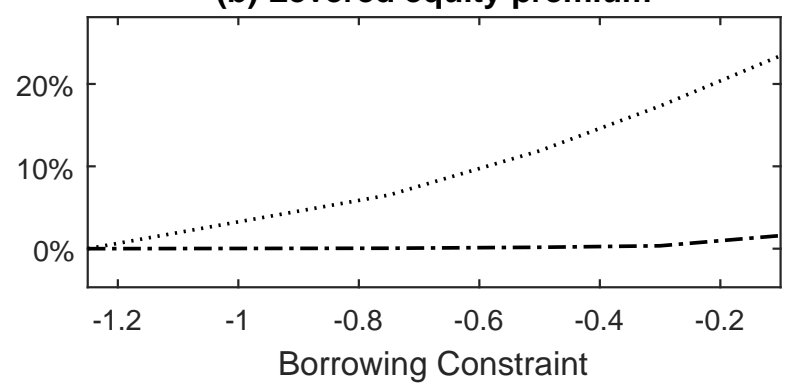

(d) Bond turnover

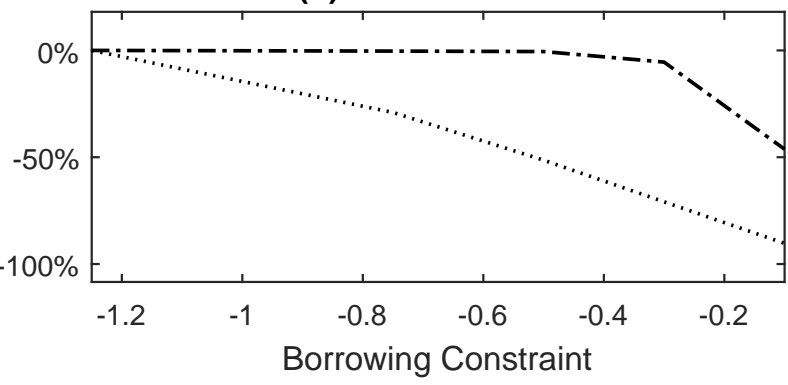

(f) Capital investment (\%output)

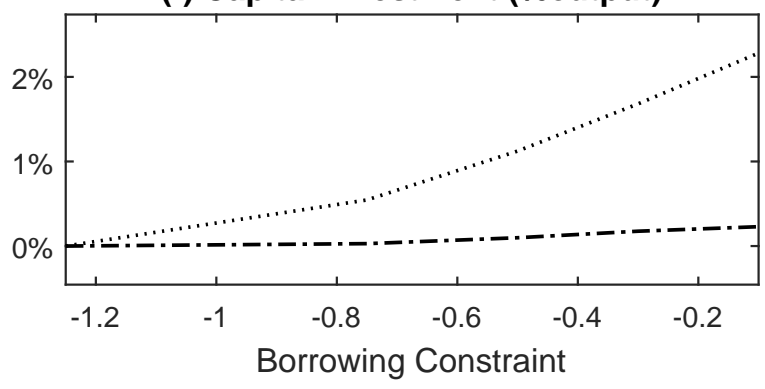

(h) Welfare

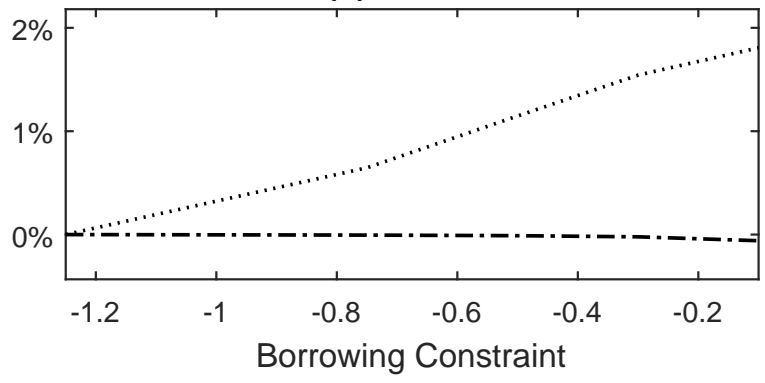

With Disagreement -.--Without Disagreement

The eight panels in this figure show how constraining borrowing changes various financial and macroeconomic quantities. The dotted line is for the economy with disagreement between the two classes of investors and the dash-dotted line is for the economy without disagreement. 
Figure 5: Effect of Tobin tax (measured in changes)

(a) Interest rate

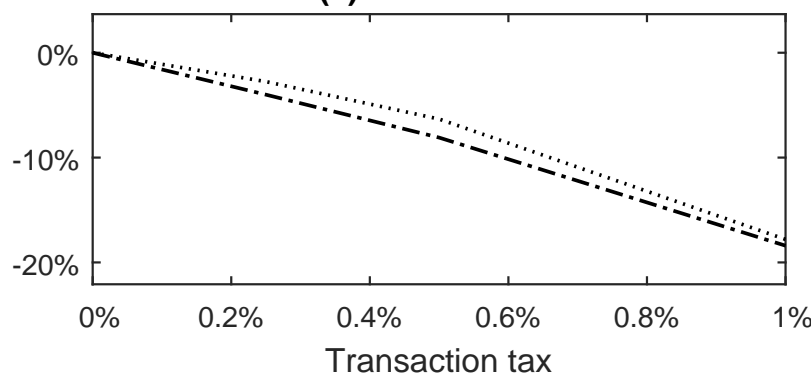

(c) Levered stock return volatility

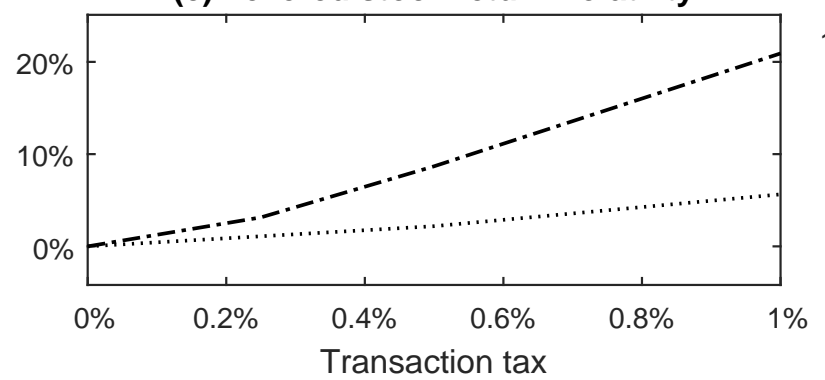

(e) Stock turnover

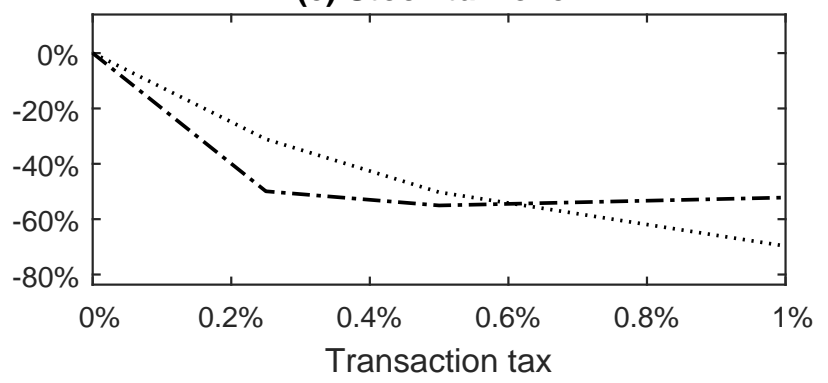

(g) Output growth

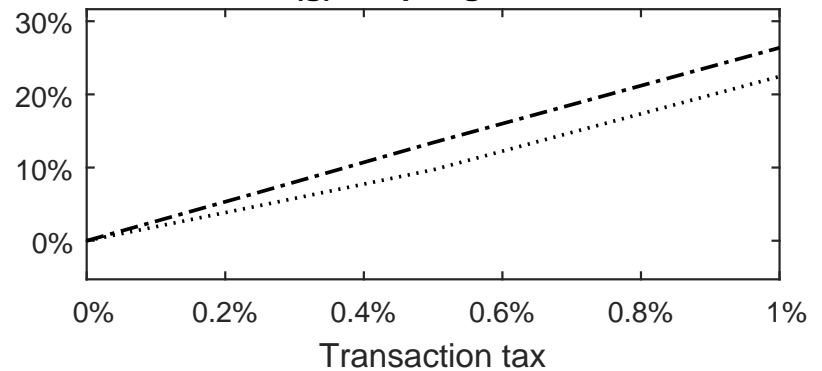

(b) Levered equity premium

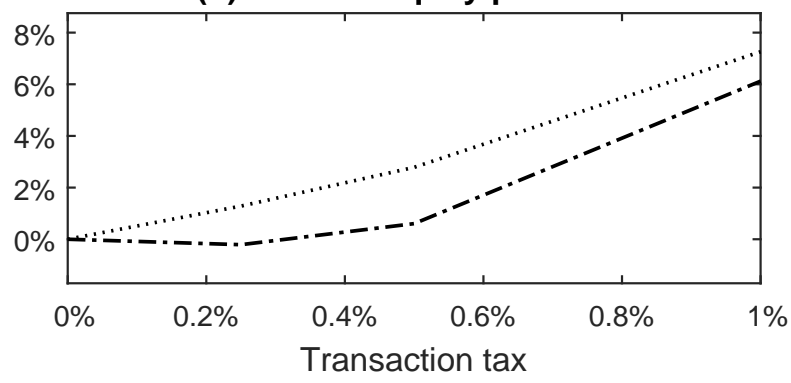

(d) Bond turnover

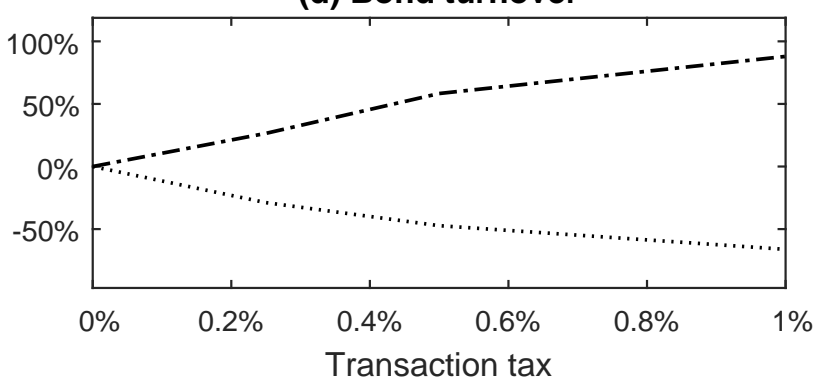

(f) Capital investment (\%output)

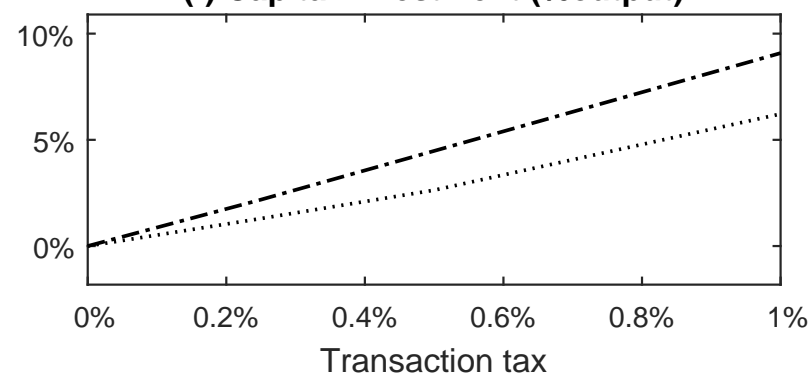

(h) Welfare

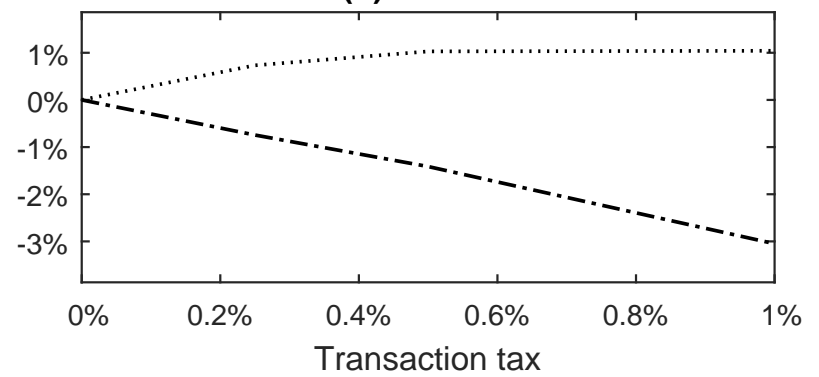

With Disagreement ---·- Without Disagreement

The eight panels in this figure show how a Tobin financial-transaction tax on trading the stock changes various financial and macroeconomic quantities. The dotted line is for the economy with disagreement between the two classes of investors and the dash-dotted line is for the economy without disagreement. 


\section{Online Appendix}

In this appendix, we first provide the derivations for the characterization of equilibrium. Next, we present the steady-state distributions of productivity as well as the first investor's consumption share. Finally, the appendix contains the figures presented in the paper, but with the relevant quantities shown in levels instead of changes.

\section{A Characterization of equilibrium}

We first discuss the firm's optimization problem and then the investors' optimization problem without and with financial regulation. At the end of the section, we describe the numerical algorithm used to solve the model.

\section{A.1 Derivations of Optimality Conditions}

\section{A.1.1 Optimality Conditions: Representative Firm}

The objective of the firm is to choose investment $I_{t}$ and labor $L_{t}$ to maximize its value, given in equation (3), subject to the law-of-motion of capital, as outlined in equation (2). Computing the first-order condition with respect to labor $L_{t}$ results in

$$
\frac{\partial \mathcal{P}_{t}}{\partial L_{t}}=\frac{\partial Y_{t}}{\partial L_{t}}-W_{t}=(1-\alpha) Z_{t} K_{t} L_{t}^{-\alpha}-W_{t}=0
$$

Using the result that, on aggregate, investors always provide one unit of labor, we get

$$
W_{t}=(1-\alpha) Z_{t} K_{t}=(1-\alpha) Y_{t}
$$

so that dividends of the firm can be rewritten as: $D_{t}=\alpha Y_{t}-I_{t}$. Plugging this into the optimization problem of the firm and maximizing with respect to $I_{t}$ gives:

$$
\frac{\partial \mathcal{P}_{t}}{\partial I_{t}}=-1+\sum_{j=1}^{J} q_{t+1, j} \frac{\partial \mathcal{P}_{t+1, j}}{\partial K_{t+1, j}}\left(1-\xi \frac{I_{t}}{K_{t}}\right)=0
$$


Invoking the envelope condition, we get:

$$
\begin{aligned}
\frac{\partial \mathcal{P}_{t}}{\partial K_{t}} & =\left(\alpha Z_{t}-\frac{\partial I_{t}}{\partial K_{t}}\right)+\left(\sum_{j=1}^{J} q_{t+1, j} \frac{\partial \mathcal{P}_{t+1, j}}{\partial K_{t+1, j}}\right) \frac{\partial K_{t+1}}{\partial K_{t}} \\
& =\alpha Z_{t}-\frac{\partial I_{t}}{\partial K_{t}}+\frac{1}{1-\xi \frac{I_{t}}{K_{t}}} \frac{\partial K_{t+1}}{\partial K_{t}} \\
& =\alpha Z_{t}-\frac{\partial I_{t}}{\partial K_{t}}+\frac{1}{1-\xi \frac{I_{t}}{K_{t}}}\left((1-\delta)+\frac{\partial I_{t}}{\partial K_{t}}-\frac{\xi}{2}\left(\frac{I_{t}}{K_{t}}\right)^{2}-\xi \frac{I_{t}}{K_{t}}\left(\frac{\partial I_{t}}{\partial K_{t}}-\frac{I_{t}}{K_{t}}\right)\right) \\
& =\alpha Z_{t}+\frac{1-\delta+\xi \frac{I_{t}}{K_{t}}}{1-\xi \frac{I_{t}}{K_{t}}}
\end{aligned}
$$

where we used equation (A3) in the second step to substitute the expectation. Plugging (A7), for time $t+1$, into (A3), we get equation (14) in the paper:

$$
\left(1-\xi \frac{I_{t}}{K_{t}}\right) \times \sum_{j=1}^{J} q_{t+1, j}\left(\alpha Z_{t+1, j}+\frac{1-\delta+\frac{\xi}{2}\left(\frac{I_{t+1, j}}{K_{t+1}}\right)^{2}}{1-\xi \frac{I_{t+1, j}}{K_{t+1}}}\right)=1
$$

\section{A.1.2 Optimality Conditions: Investors in Absence of Regulatory Measures}

The objective of each investor $i$ is to maximize lifetime utility given in (4), subject to the

flow budget equation (5), by choosing consumption, $c_{i, t}$, and the portfolio position $\theta_{i, t}^{\{B, S\}}$ in each of the two financial assets. The Lagrangian associated with this problem is given by:

$$
\begin{aligned}
\mathcal{L}_{i, t} & =\sup _{c_{i, t}, \theta_{i, t}^{S}, \theta_{i, t}^{B}} \inf _{R_{i, t}^{B C}}\left[(1-\beta) c_{i, t}^{1-\frac{1}{\psi}}+\beta \mathbb{E}_{t}^{i}\left[V_{i, t+1}^{1-\gamma}\right]^{\frac{1}{\phi}}\right]^{\frac{\phi}{1-\gamma}} \\
& +R_{i, t}^{B C}\left[e_{i, t} W_{t}+\theta_{i, t-1}^{B}+\theta_{i, t-1}^{S}\left(S_{t}+D_{t}\right)-c_{i, t}-\theta_{i, t}^{S} S_{t}-\theta_{i, t}^{B} B_{t}\right],
\end{aligned}
$$

where $R_{i, t}^{B C}$ denotes the Lagrange multiplier associated with the budget equation. 
The first-order condition of (A9) with respect to consumption $c_{i, t}$ is given by:

$$
\begin{aligned}
\frac{\partial \mathcal{L}_{i, t}}{\partial c_{i, t}} & =\frac{1}{1-\frac{1}{\psi}}\left\{(1-\beta) c_{i, t}^{1-\frac{1}{\psi}}+\beta \mathbb{E}_{t}^{i}\left[V_{i, t+1}^{1-\gamma}\right]^{\frac{1-\frac{1}{\psi}}{1-\gamma}}\right\}^{\frac{1}{1-\frac{1}{\psi}}-1}(1-\beta)\left(1-\frac{1}{\psi}\right) c_{i, t}^{1-\frac{1}{\psi}-1}-R_{i, t}^{B C} \\
& =(1-\beta) c_{i, t}^{-\frac{1}{\psi}}\left[\left\{(1-\beta) c_{i, t}^{1-\frac{1}{\psi}}+\beta \mathbb{E}_{t}^{i}\left[V_{i, t+1}^{1-\gamma}\right]^{\frac{1-\frac{1}{\psi}}{1-\gamma}}\right\}^{\frac{1}{1-\frac{1}{\psi}}}\right]^{\frac{1}{\psi}}-R_{i, t}^{B C} \\
& =(1-\beta) c_{i, t}^{-\frac{1}{\psi}} V_{i, t}^{\frac{1}{\psi}}-R_{i, t}^{B C} \equiv 0 .
\end{aligned}
$$

Second, the first-order condition of (A9) with respect to the Lagrange multiplier $R_{i, t}^{B C}$ :

$$
\frac{\partial \mathcal{L}_{i, t}}{\partial R_{i, t}^{B C}}=\left[e_{i, t} W_{t}+\theta_{i, t-1}^{B}+\theta_{i, t-1}^{S}\left(S_{t}+D_{t}\right)-\theta_{t}^{B} B_{t}-\theta_{i, t}^{S} S_{t}-c_{i, t}\right] \equiv 0 .
$$

Third, the first-order condition of (A9) with respect to the bond holdings $\theta_{i, t}^{B}$ :

$$
\begin{aligned}
\frac{\partial \mathcal{L}_{i, t}}{\partial \theta_{i, t}^{B}}= & \frac{1}{1-\frac{1}{\psi}}\left\{(1-\beta) c_{i, t}^{1-\frac{1}{\psi}}+\beta \mathbb{E}_{t}^{i}\left[V_{i, t+1}^{1-\gamma}\right]^{\frac{1-\frac{1}{\psi}}{1-\gamma}}\right\}^{\frac{1}{1-\frac{1}{\psi}}-1} \times \\
& \beta \frac{1-\frac{1}{\psi}}{1-\gamma} \mathbb{E}_{t}^{i}\left[V_{i, t+1}^{1-\gamma}\right]^{\frac{1-\frac{1}{\psi}}{1-\gamma}-1}(1-\gamma) \mathbb{E}_{t}^{i}\left[V_{i, t+1}^{-\gamma} \frac{\partial V_{i, t+1}}{\partial \theta_{i, t}^{B}}\right]-R_{i, t}^{B C} B_{t} \\
= & \beta V_{i, t}^{\frac{1}{\psi}} \mathbb{E}_{t}^{i}\left[V_{i, t+1}^{1-\gamma}\right]^{\frac{1-\frac{1}{\psi}}{1-\gamma}-1} \mathbb{E}_{t}^{i}\left[V_{i, t+1}^{-\gamma} \frac{\partial V_{i, t+1}}{\partial \theta_{i, t}^{B}}\right]-R_{i, t}^{B C} B_{t} \equiv 0,
\end{aligned}
$$

and the first-order condition with respect to the stock holdings $\theta_{i, t}^{S}$ :

$$
\begin{aligned}
\frac{\partial \mathcal{L}_{i, t}}{\partial \theta_{i, t}^{S}}= & \frac{1}{1-\frac{1}{\psi}}\left\{(1-\beta) c_{i, t}^{1-\frac{1}{\psi}}+\beta \mathbb{E}_{t}^{i}\left[V_{i, t+1}^{1-\gamma}\right]^{\frac{1-\frac{1}{\psi}}{1-\gamma}}\right\}^{\frac{1}{1-\frac{1}{\psi}}-1} \times \\
& \beta \frac{1-\frac{1}{\psi}}{1-\gamma} \mathbb{E}_{t}^{i}\left[V_{i, t+1}^{1-\gamma}\right]^{\frac{1-\frac{1}{\psi}}{1-\gamma}-1}(1-\gamma) \mathbb{E}_{t}^{i}\left[V_{i, t+1}^{-\gamma} \frac{\partial V_{i, t+1}}{\partial \theta_{i, t}^{S}}\right]-R_{i, t}^{B C} S_{t} \\
= & \beta V_{i, t}^{\frac{1}{\psi}} \mathbb{E}_{t}^{i}\left[V_{i, t+1}^{1-\gamma}\right]^{\frac{1-\frac{1}{\psi}}{1-\gamma}-1} \mathbb{E}_{t}^{i}\left[V_{i, t+1}^{-\gamma} \frac{\partial V_{i, t+1}}{\partial \theta_{i, t}^{S}}\right]-R_{i, t}^{B C} S_{t} \equiv 0 .
\end{aligned}
$$

Invoking the envelope theorem, we can replace the derivative of the value function with the partial derivative of the Lagrangian, assuming that the decision variables are 
at their optimum, and hence, the first-order conditions with respect to decision variables are satisfied. Differentiating the original Lagrangian (A9) with respect to past holdings, we get:

$$
\begin{aligned}
\frac{\partial V_{i, t}}{\partial \theta_{i, t-1}^{B}} & =\frac{\partial \mathcal{L}_{i, t}}{\partial \theta_{i, t-1}^{B}}=R_{i, t}^{B C}, \\
\frac{\partial V_{i, t}}{\partial \theta_{i, t-1}^{S}} & =\frac{\partial \mathcal{L}_{i, t}}{\partial \theta_{i, t-1}^{S}}=R_{i, t}^{B C} \times\left(S_{i, t}+D_{t}\right) .
\end{aligned}
$$

To summarize, the first-order conditions that characterize the investors' optimization problem are given by:

$$
\begin{aligned}
c_{i, t}+\theta_{i, t}^{B} B_{t}+\theta_{i, t}^{S} S_{t} & =\theta_{i, t-1}^{B}+\theta_{i, t-1}^{S}\left(D_{t}+S_{t}\right)+e_{i, t} W_{t}, \\
B_{t} & =\mathbb{E}_{t}^{i}\left[\frac{M_{i, t+1}}{M_{i, t}}\right], \\
S_{t} & =\mathbb{E}_{t}^{i}\left[\frac{M_{i, t+1}}{M_{i, t}} \times\left(S_{t+1}+D_{t+1}\right)\right],
\end{aligned}
$$

where $\frac{M_{i, t+1}}{M i, t}$ denotes the investors' pricing kernel for Epstein-Zin-Weil utility:

$$
\frac{M_{i, t+1}}{M_{i, t}}=\beta\left(\frac{V_{i, t+1}^{1-\gamma}}{\mathbb{E}_{t}^{i}\left[V_{i, t+1}^{1-\gamma}\right]}\right)^{\frac{\frac{1}{\psi}-\gamma}{1-\gamma}}\left(\frac{c_{i, t+1}}{c_{i, t}}\right)^{-\frac{1}{\psi}}
$$

Equation (A16) is the budget constraint that the consumption and portfolio policies must satisfy. Intuitively, equations (A17) and (A18) equate the benefit from holding an asset to the benefit from selling it.

\section{A.1.3 Optimality Conditions: Investors in Presence of Regulatory Measures}

We now derive the optimality conditions for the setups with a constraint on stock holdings, a borrowing constraint, and the Tobin tax on stock transactions.

\section{Portfolio Constraint}

The Lagrangian associated with lifetime utility (4), the budget constraint (5), and the 
portfolio constraint (11) is given by:

$$
\begin{aligned}
\mathcal{L}_{i, t} & =\sup _{c_{i, t}, \theta_{i, t}^{S}} \inf _{R_{i, t}^{B C}, R_{i, t}^{S}}\left[(1-\beta) c_{i, t}^{1-\frac{1}{\psi}}+\beta \mathbb{E}_{t}^{i}\left[V_{i, t+1}^{1-\gamma}\right]^{\frac{1}{\phi}}\right]^{\frac{\phi}{1-\gamma}} \\
& +R_{i, t}^{B C}\left[e_{i, t} W_{t}+\theta_{i, t-1}^{B}+\theta_{i, t-1}^{S}\left(S_{t}+D_{t}\right)-c_{i, t}-\theta_{i, t}^{S} S_{t}-\theta_{i, t}^{B} B_{t}\right] \\
& +R_{i, t}^{B C} R_{i, t}^{S} S_{t} \times\left(\theta_{i, t}^{S}-\rho\right),
\end{aligned}
$$

where $R_{i, t}^{B C}$ and $R_{i, t}^{B C} R_{i, t}^{S} S_{t}$ denote the Lagrange multipliers associated with the budget constraint and the portfolio constraint, respectively.

The derivations are similar to the derivations for the economy without regulation discussed above. Only the first-order condition with respect to the stock holdings changes to:

$$
\frac{\partial \mathcal{L}_{i, t}}{\partial \theta_{i, t}^{S}}=\beta V_{i, t}^{\frac{1}{\psi}} \mathbb{E}_{t}^{i}\left[V_{i, t+1}^{1-\gamma}\right]^{\frac{1-\frac{1}{\psi}}{1-\gamma}-1} \mathbb{E}_{t}^{i}\left[V_{i, t+1}^{-\gamma} \frac{\partial V_{i, t+1}}{\partial \theta_{i, t}^{S}}\right]-R_{i, t}^{B C} S_{t}+R_{i, t}^{B C} R_{i, t}^{S} S_{t} \equiv 0
$$

such that the kernel condition of the stock becomes

$$
S_{i, t}=\frac{1}{1-R_{i, t}^{S}} \times \mathbb{E}_{t}^{i}\left[\frac{M_{i, t+1}}{M_{i, t}}\left(S_{i, t+1}+D_{t+1}\right)\right] .
$$

In addition, we get the following complimentary slackness and inequality conditions:

$$
R_{i, t}^{S} \times\left(\theta_{i, t}^{S}-\rho\right)=0 ; \quad R_{i, t}^{S} \geq 0 ; \quad \theta_{i, t}^{S} \geq \rho .
$$

\section{Borrowing Constraint}

The Lagrangian associated with lifetime utility (4), the budget constraint (5), and the borrowing constraint (12), is:

$$
\begin{aligned}
\mathcal{L}_{i, t} & =\sup _{c_{i, t}, \theta_{i, t}^{S}, \theta_{i, t}^{B}} \inf _{R_{i, t}^{B C}, R_{i, t}^{B}}\left[(1-\beta) c_{i, t}^{1-\frac{1}{\psi}}+\beta \mathbb{E}_{t}^{i}\left[V_{i, t+1}^{1-\gamma}\right]^{\frac{1}{\phi}}\right]^{\frac{\phi}{1-\gamma}} \\
& +R_{i, t}^{B C}\left[e_{i, t} W_{t}+\theta_{i, t-1}^{B}+\theta_{i, t-1}^{S}\left(S_{t}+D_{t}\right)-c_{i, t}-\theta_{i, t}^{S} S_{t}-\theta_{i, t}^{B} B_{t}\right] \\
& +R_{i, t}^{B C} R_{i, t}^{B} \times\left(\theta_{i, t}^{B} B_{t}-\kappa Y_{t}\right),
\end{aligned}
$$


where $R_{i, t}^{B C}$ and $R_{i, t}^{B C} R_{i, t}^{B}$ denote the Lagrange multipliers associated with the budget constraint and the borrowing constraint, respectively.

The derivations are similar to the ones for the portfolio constraint above, and the only difference is that now instead of the stock, it is the bond holdings that are constrained, so that only the kernel condition of the bond changes compared to the setup without financial regulation:

$$
B_{i, t}=\frac{1}{1-R_{i, t}^{B}} \times \mathbb{E}_{t}^{i}\left[\frac{M_{i, t+1}}{M_{i, t}}\right]
$$

The complimentary slackness and inequality conditions are:

$$
R_{i, t}^{B} \times\left(\theta_{i, t}^{B} B_{t}-\kappa Y_{t}\right)=0 ; \quad R_{i, t}^{S} \geq 0 ; \quad \theta_{i, t}^{B} B_{t} \geq \kappa Y_{t}
$$

\section{Financial Transactions (Tobin) Tax}

To deal with the financial transaction tax, we follow Buss and Dumas (2015) and rewrite the optimality conditions in terms of a dual formulation with an investor-specific Lagrange multiplier $R_{i, t}^{T T}$ that captures the (shadow) cost of trading in the stock. First, we rewrite the flow budget constraint (5) to take into account the costs of buying and selling the stock:

$$
c_{i, t}+\theta_{i, t}^{B} B_{t}+\theta_{i, t}^{S} S_{t}+\tau\left(\hat{\theta}_{i, t}^{S}+\check{\theta}_{i, t}^{S}\right) S_{t}=\theta_{i, t-1}^{B}+\theta_{i, t-1}^{S}\left(D_{t}+S_{t}\right)+e_{i, t} W_{t}+\chi_{i, t},
$$

where $\hat{\theta}_{i, t}^{S} \geq 0$ and $\check{\theta}_{i, t}^{S} \geq 0$ denote the number of shares sold and bought, respectively, which are linked to the investors' stock holdings through $\theta_{i, t}^{S}=\theta_{i, t-1}^{S}-\hat{\theta}_{i, t}^{S}+\check{\theta}_{i, t}^{S}$. Here $\tau_{t}$ denotes the level of transaction tax, and $\chi_{i, t}$ is the lump-sum transfer back to the investors after they have made their optimization decisions. Using the number of shares bought and sold allows one to replace the absolute-value operator, making the problem more suitable for numerical optimization.

Forming the Lagrangian associated with lifetime utility (4), the modified flow budget constraint (A27) with associated Lagrange multiplier $R_{i, t}^{B C}$, and the two inequality con- 
ditions $\left(\hat{\theta}_{i, t}^{S} \geq 0\right.$ and $\left.\check{\theta}_{i, t}^{S} \geq 0\right)$ with multipliers $\mu_{1, i, t}$ and $\mu_{2, i, t}$ for the selling and buying decision, we get:

$$
\begin{aligned}
\mathcal{L}_{i, t} & =\sup _{c_{i, t}, \theta_{i, t}^{B}, \check{\theta}_{i, t}^{S}, \hat{\theta}_{i, t}^{S}} \inf _{R_{i, t}^{B C}, \mu_{1, i, t}, \mu_{2, i, t}}\left[(1-\beta) c_{i, t}^{1-\frac{1}{\psi}}+\beta \mathbb{E}_{t}^{i}\left[V_{i, t+1}^{1-\gamma}\right]^{\frac{1}{\phi}}\right]^{\frac{\phi}{1-\gamma}} \\
& +R_{i, t}^{B C}\left[e_{i, t} W_{t}+\xi_{i, t} \theta_{i, t-1}^{B}+\theta_{i, t-1}^{S}\left(S_{t}+D_{t}\right)-c_{i, t}-\theta_{i, t}^{S} S_{t}+\tau\left(\hat{\theta}_{i, t}^{S}+\check{\theta}_{i, t}^{S}\right) S_{t}-\theta_{i, t}^{B} B_{t}\right] \\
& +\mu_{1, i, t} \times \hat{\theta}_{i, t}^{S}+\mu_{2, i, t} \times \check{\theta}_{i, t}^{S},
\end{aligned}
$$

with $\theta_{i, t}^{S}=\theta_{i, t-1}^{S}-\hat{\theta}_{i, t}^{S}+\check{\theta}_{i, t}^{S}$.

Differentiating the resulting Lagrangian with respect to current consumption $c_{i, t}$, with respect to bond holdings, and with respect to the new variables $\hat{\theta}_{i, t}^{S}$ and $\check{\theta}_{i, t}^{S}$ for the stock, we obtain the following first-order conditions:

$$
\begin{gathered}
(1-\beta) c_{i, t}^{-\frac{1}{\psi}} V_{i, t}^{\frac{1}{\psi}}=R_{i, t}^{B C} \\
\beta V_{i, t}^{\frac{1}{\psi}} \mathbb{E}_{t}^{i}\left[V_{i, t+1}^{1-\gamma}\right]^{\frac{1-\frac{1}{\psi}}{1-\gamma}-1} \mathbb{E}_{t}^{i}\left[V_{i, t+1}^{-\gamma} \frac{\partial V_{i, t+1}}{\partial \theta_{i, t}^{S}}\right]=-R_{i, t}^{B C}(1+\tau) S_{i, t}+\mu_{1, i, t} \\
\beta V_{i, t}^{\frac{1}{\psi}} \mathbb{E}_{t}^{i}\left[V_{i, t+1}^{1-\gamma}\right]^{\frac{1-\frac{1}{\psi}}{1-\gamma}-1} \mathbb{E}_{t}^{i}\left[V_{i, t+1}^{-\gamma} \frac{\partial V_{i, t+1}}{\partial \theta_{i, t}^{S}}\right]=R_{i, t}^{B C}(1-\tau) S_{i, t}+\mu_{2, i, t} \\
\beta V_{i, t}^{\frac{1}{\psi}} \mathbb{E}_{t}^{i}\left[V_{i, t+1}^{1-\gamma}\right]^{\frac{1-\frac{1}{\psi}}{1-\gamma}-1} \mathbb{E}_{t}^{i}\left[V_{i, t+1}^{-\gamma} \frac{\partial V_{i, t+1}}{\partial \theta_{i, t}^{B}}\right]=R_{i, t}^{B C} B_{t} \\
c_{i, t}+\theta_{i, t}^{B} B_{t}+\theta_{i, t}^{S} S_{t}+\tau\left(\hat{\theta}_{i, t}^{S}+\check{\theta}_{i, t}^{S}\right) S_{t}=\theta_{i, t-1}^{B}+\theta_{i, t-1}^{S}\left(D_{t}+S_{t}\right)+e_{i, t} W_{t}+\chi_{i, t}, \\
\mu_{1, i, t} \hat{\theta}_{i, t}^{S}=0, \quad \mu_{2, i, t} \check{\theta}_{i, t}^{S}=0, \quad \mu_{\{1,2\}, i, t} \geq 0, \quad \hat{\theta}_{i, t}^{S} \geq 0, \quad \check{\theta}_{i, t}^{S} \geq 0 .
\end{gathered}
$$

Note that equations (A30) and (A31) imply

$$
-R_{i, t}^{B C}(1+\tau) S_{i, t}+\mu_{1, i, t}=R_{i, t}^{B C}(1-\tau) S_{i, t}+\mu_{2, i, t}
$$

so that we can replace the two multipliers $\mu_{\{1,2\}, k, t}$ with one multiplier $R_{i, t}^{T T}$, defined as:

$$
R_{i, t}^{B C} R_{i, t}^{T T} S_{i, t} \stackrel{\text { def }}{=}-R_{i, t}^{B C}(1+\tau) S_{i, t}+\mu_{1, i, t}=R_{i, t}^{B C}(1-\tau) S_{i, t}+\mu_{2, i, t}
$$


From (A36), it follows that

$$
\begin{aligned}
& \mu_{1, i, t}=R_{i, t}^{B C} S_{i, t}\left(R_{i, t}^{T T}+1+\tau\right), \\
& \mu_{2, i, t}=R_{i, t}^{B C} S_{i, t}\left(R_{i, t}^{T T}-1+\tau\right),
\end{aligned}
$$

so that we can rewrite the slackness conditions respectively:

$$
\begin{aligned}
& \left(R_{i, t}^{T T}+1+\tau\right) \check{\theta}_{i, t}^{S}=0, \\
& \left(R_{i, t}^{T T}-1+\tau\right) \hat{\theta}_{i, t}^{S}=0 .
\end{aligned}
$$

Using the slackness conditions, we can rewrite the flow budget equation as follows:

$$
e_{i, t} W_{t}+\chi_{i, t}+\theta_{k, t-1}^{S} D_{t}-c_{i, t}+\theta_{k, t-1}^{B}-\theta_{k, t}^{B} B_{i, t}-\left(\theta_{k, t}^{S}-\theta_{k, t-1}^{S}\right) S_{i, t} R_{i, t}^{T T}=0 .
$$

Now, apply the Envelope Theorem to get rid of the value function in the first-order conditions:

$$
\begin{aligned}
& \frac{\partial V_{k, t+1}}{\partial \theta_{k, t}^{B}}=R_{i, t+1}^{B C} B_{k, t+1}, \\
& \frac{\partial V_{k, t+1}}{\partial \theta_{k, t}^{S}}=R_{i, t+1}^{B C}\left(R_{i, t+1}^{T T} S_{t+1}+D_{t+1}\right),
\end{aligned}
$$

and finally get the following system:

$$
\begin{gathered}
S_{t}=\frac{1}{R_{i, t}^{T T}} \times \mathbb{E}_{t}^{i}\left[\frac{M_{i, t+1}}{M_{i, t}}\left(R_{i, t+1}^{T T} S_{t+1}+D_{t+1}\right)\right], \\
B_{t}=\mathbb{E}_{t}^{i}\left[\frac{M_{i, t+1}}{M_{i, t}}\right], \\
c_{i, t}+\left(\theta_{i, t}^{S}-\theta_{i, t-1}^{S}\right) S_{i, t} R_{i, t}^{T T}+\theta_{k, t}^{B} B_{i, t}=\theta_{k, t-1}^{S} D_{t}+\theta_{k, t-1}^{B}+\chi_{i, t}+e_{i, t} W_{t}, \\
\left(R_{i, t}^{T T}+1+\tau\right) \check{\theta}_{i, t}^{S}=0, \quad\left(R_{i, t}^{T T}-1+\tau\right) \hat{\theta}_{i, t}^{S}=0, \\
1-\tau \leq R_{i, t}^{T T} \leq 1+\tau ; \quad \hat{\theta}_{i, t}^{S} \geq 0 ; \quad \check{\theta}_{i, t}^{S} \geq 0 .
\end{gathered}
$$




\section{A.2 Equilibrium: Numerical Solution Method}

The numerical method we use is not based on an approximation of any sort; ${ }^{20}$ it is exact (except for local interpolation and, of course, numerical truncation error), which is a distinct advantage considering the non linearities involved.

We wish to obtain the equilibrium in a numerical form by backward-induction. For reasons explained in Dumas and Lyasoff (2012), the system of first-order conditions written in the previous appendixes cannot be solved by backward induction. However, it is possible to solve the equations by backward induction if one changes the sequence in which the equations are solved, performing a re-grouping of equations in such a way that, at a node of time $t$, one solves the equations yielding not consumption at time $t$ and the portfolio chosen at time $t$ but, instead, consumption at the various successor nodes at time $t+1$ and the portfolio at time $t$.

In this case, the first investor's share of output $\frac{c_{1, t}}{Y_{t}}$ serves as an endogeneous state variable. The capital stock $K_{t}$ is an endogenous state variable as well but, under our assumptions, a scale-invariance property holds so that it is only a scale variable, which can be factored out of all the equations.

In the same way, that is, on a grid, we treat a variable, which is, in fact, exogenous and which is imbedded in the conditional expected value operators $\mathbb{E}_{i, t}$. Beliefs differ; hence the subscript $i$ on these operators. The way in which beliefs differ has been explained in Section 2. Recall that we consider two hidden states and four observable states of a Markov chain. Investors have immutable beliefs about the transition probabilities from the two time- $t$ hidden states to the two time- $t+1$ hidden states and, from there, to the four time- $t+1$ observable states. But each of the two investors has to estimate the probability of being at time $t$ in one of the two hidden states. These estimated probabilities change

\footnotetext{
${ }^{20}$ Approximation methods commonly used are: Taylor series (the "perturbation" method) and linear combinations of polynomials (the "projection" method).
} 
over time in response to the observations made in the past. By means of simulations of the hidden Markov chain (the workings of which are exogenous to our model), we identify the full, discrete list of pairs of these estimated probabilities that can occur at any time and we place these on a grid.

In case of financial regulation, the complementary slackness conditions cause the system to be ill-defined. As in Buss and Dumas (2015), we replace them with the following:

$$
\begin{gathered}
\left(1+\tau-R_{i, t}\right) \check{\theta}_{i, t}=\varepsilon, \\
\left(-1+\tau+R_{i, t}\right) \hat{\theta}_{i, t}=\varepsilon,
\end{gathered}
$$

and, as we approach the final solution, we let $\varepsilon$ approach zero. That is called the "InteriorPoint Algorithm" (see Armand, Benoist, and Orban (2008)).

Moreover, in the case of the Tobin tax, the ratio of the investors' shadow prices $\frac{R_{1, t}^{T T}}{R_{2, t}^{T T}}$ is needed as another endogenous state variable.

\section{B Steady state distributions}

As discussed in the paper, our model of productivity growth implies a steady-state distribution for productivity, as the growth rate is mean-reverting. Figure A1, first row, shows the dynamics of the steady-state distribution of productivity over time, based on the parameters used in the paper. It also shows the standard deviation of productivity across paths which indicates that the distribution quickly (after about 25 years) approaches it steady state.

The second row of Figure A1 depicts the steady-state distribution of the first investor's consumption share which is nicely centered around 0.5 as both investors are perfectly symmetric. It also shows the dynamics of the standard deviation of the consumption share across paths over time, indicating that the distribution converges to its steady state after about 150 years. 
Figure A1: Steady-state distributions
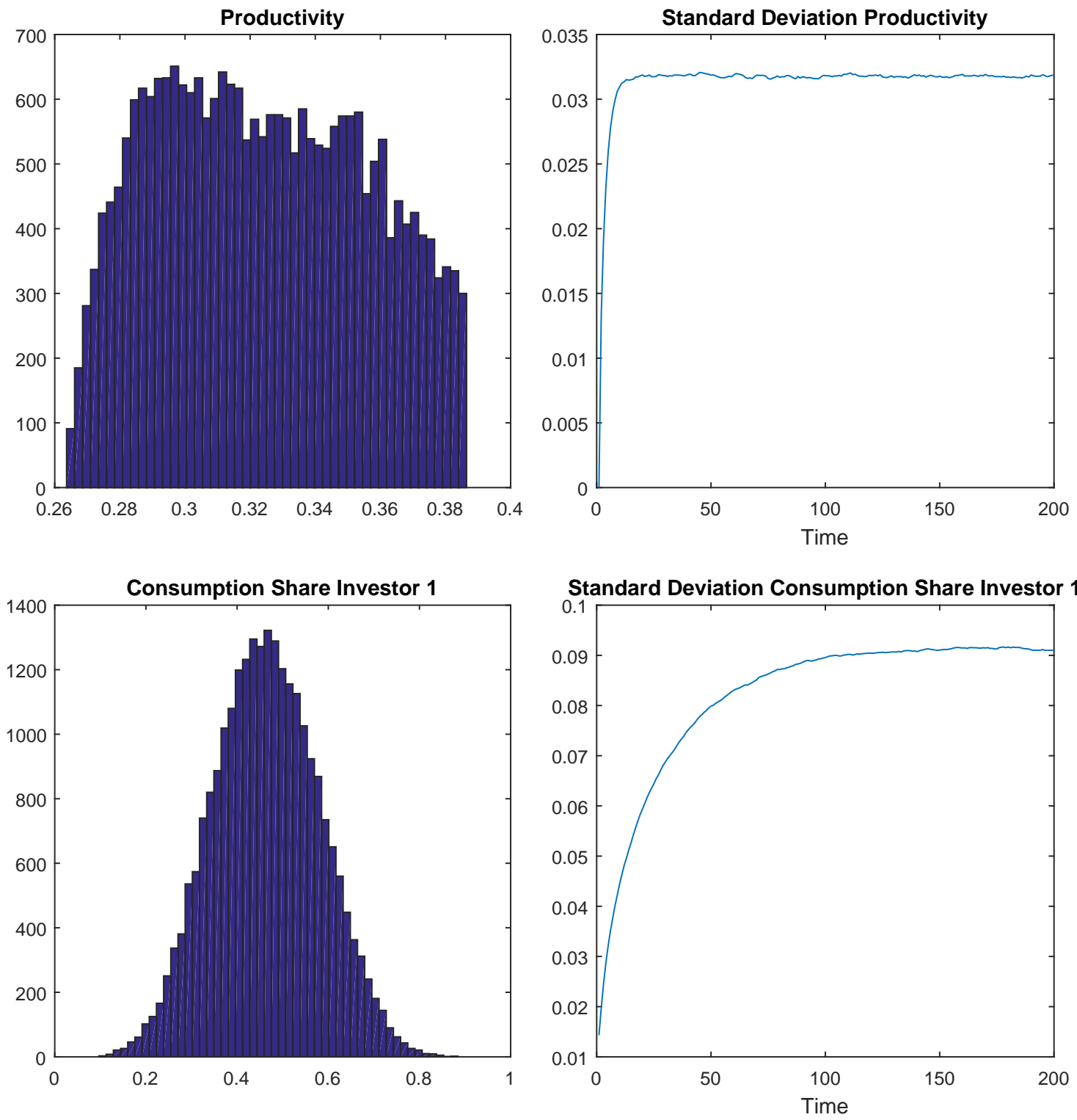

The figure shows the steady-state distributions for productivity and the first investor's consumption share (left side), together with the dynamics of the standard deviation of the variable across paths over time (right side). 


\section{Results in levels rather than changes}

The three figures below, which display the levels of the quantities of interest, correspond to the three figures in the manuscript, Figure 3, Figure 4, and Figure 5, where the quantities of interest are displayed in terms of changes.

Figure A2: Effect of constraint on stock portfolio (measured in levels)

(a) Interest rate

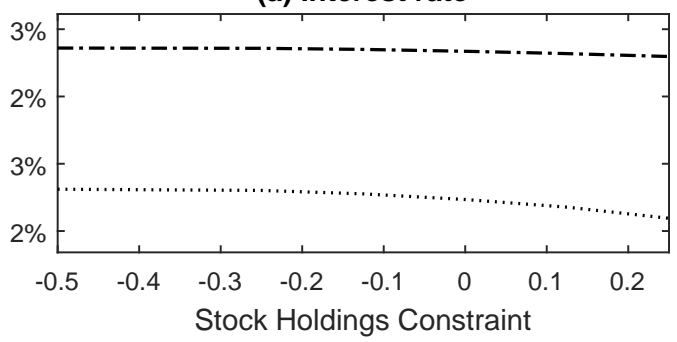

(c) Levered stock return volatility

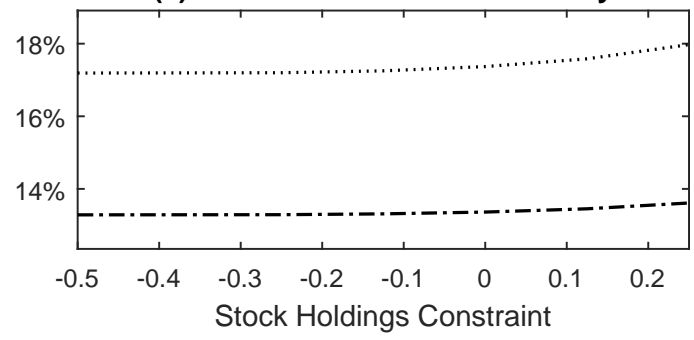

(e) Stock turnover

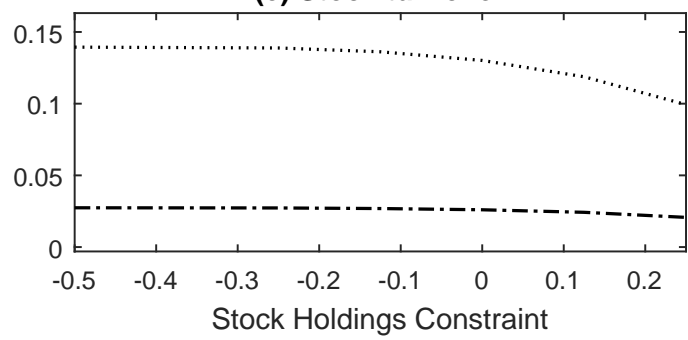

(g) Output growth

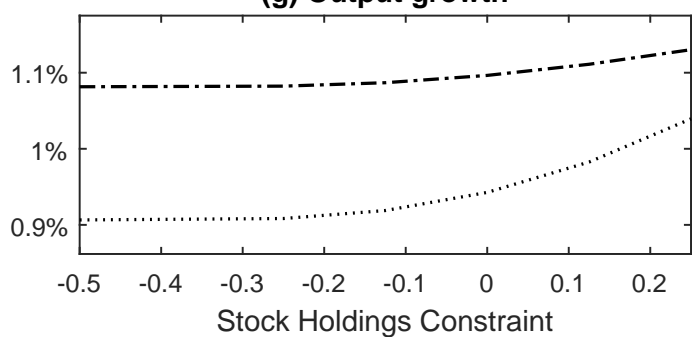

(b) Levered equity premium

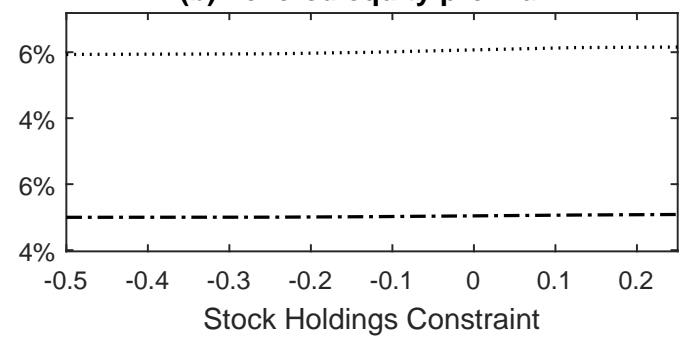

(d) Bond turnover

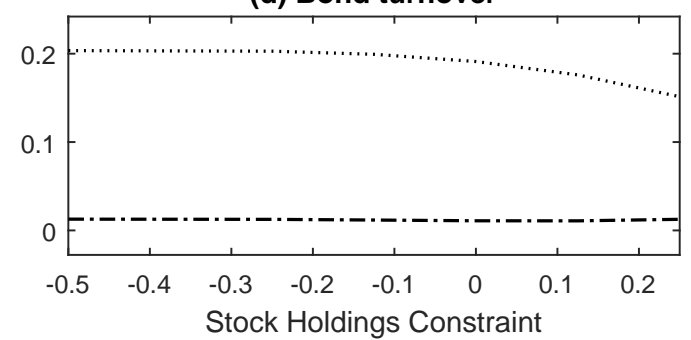

(f) Capital investment (\%output)

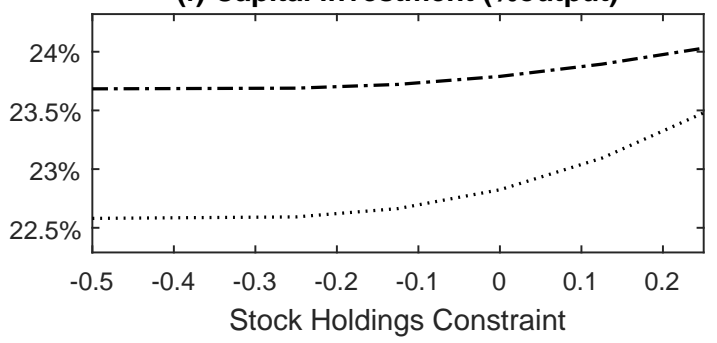

(h) Welfare

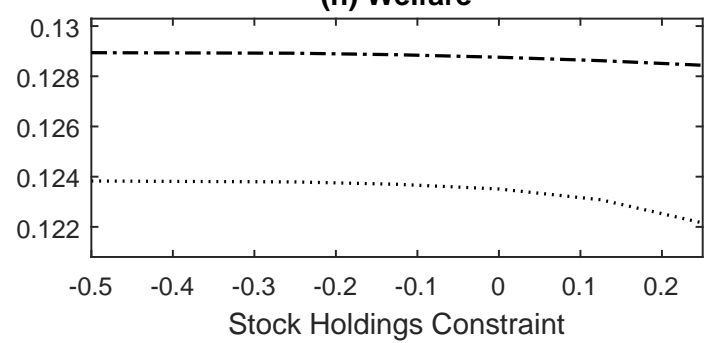

With Disagreement $-\cdot-\cdot-$ Without Disagreement

The eight panels in this figure show how constraining stock-portfolio positions affects various financial and macroeconomic quantities. The dotted line is for the economy with disagreement between the two classes of investors and the dash-dotted line is for the economy without disagreement. 
Figure A3: Effect of constraint on borrowing (measured in levels)

(a) Interest rate

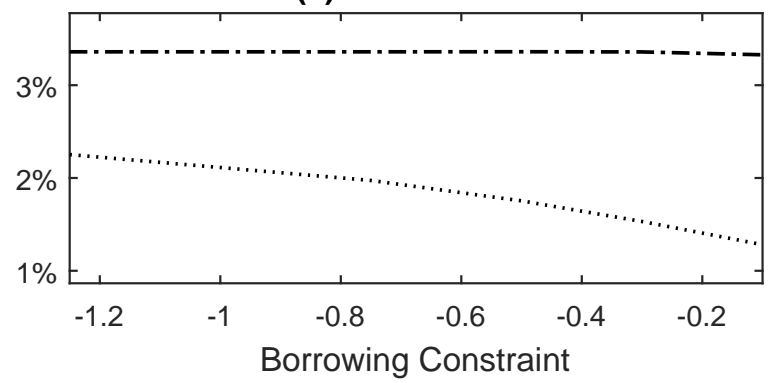

(c) Levered stock return volatility

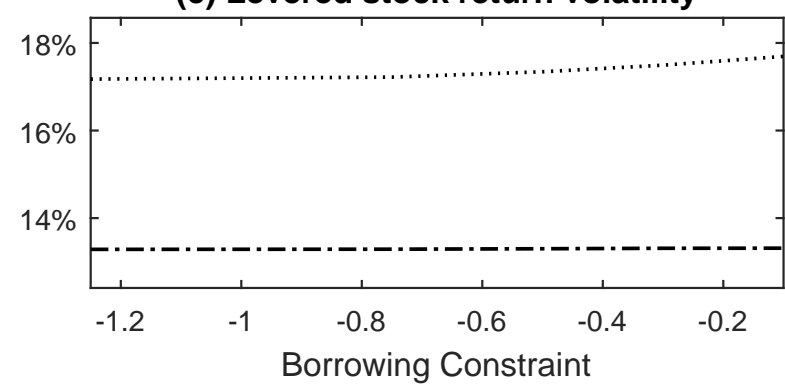

(e) Stock turnover

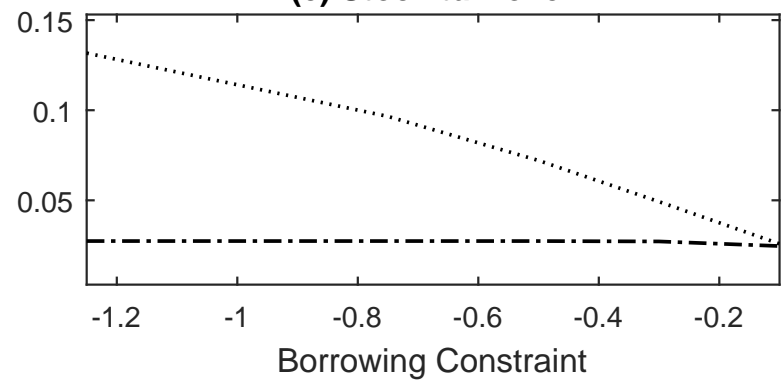

(g) Output growth

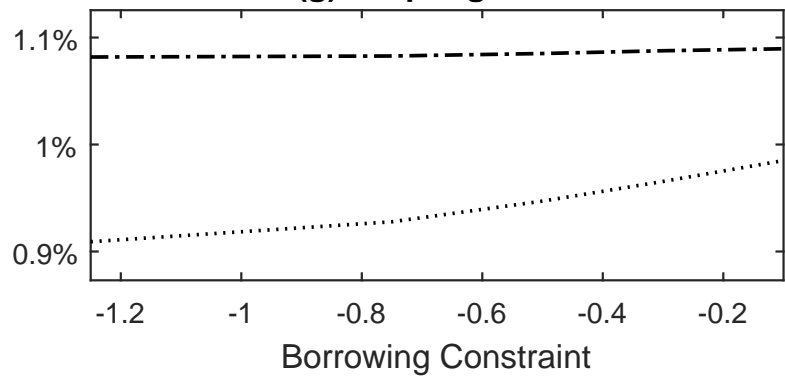

(b) Levered equity premium

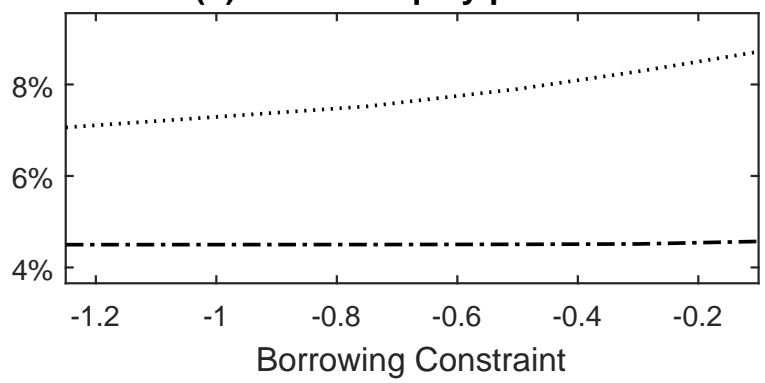

(d) Bond turnover

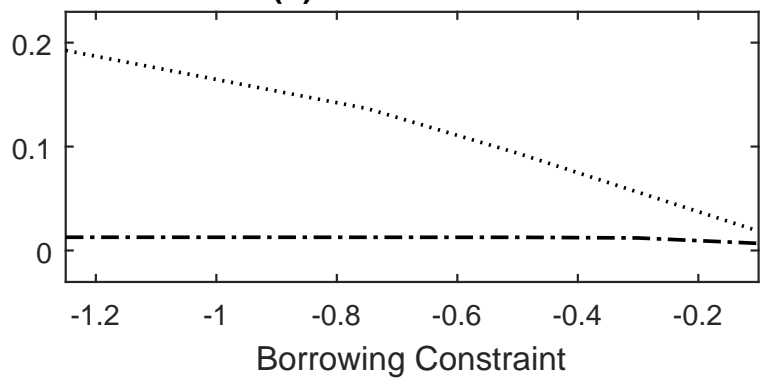

(f) Capital investment (\%output)

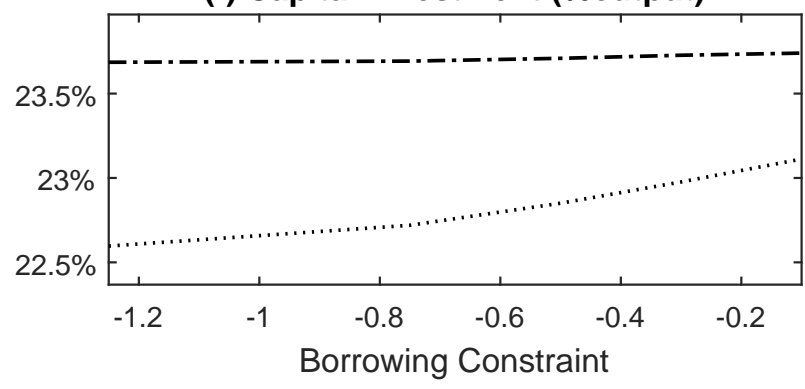

(h) Welfare

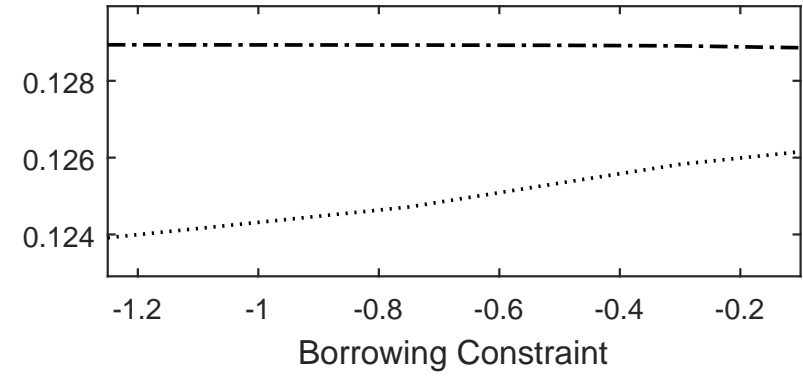

With Disagreement -.--- Without Disagreement

The eight panels in this figure show how constraining borrowing affects various financial and macroeconomic quantities. The dotted line is for the economy with disagreement between the two classes of investors and the dash-dotted line is for the economy without disagreement. 
Figure A4: Effect of Tobin tax (measured in levels)

(a) Interest rate

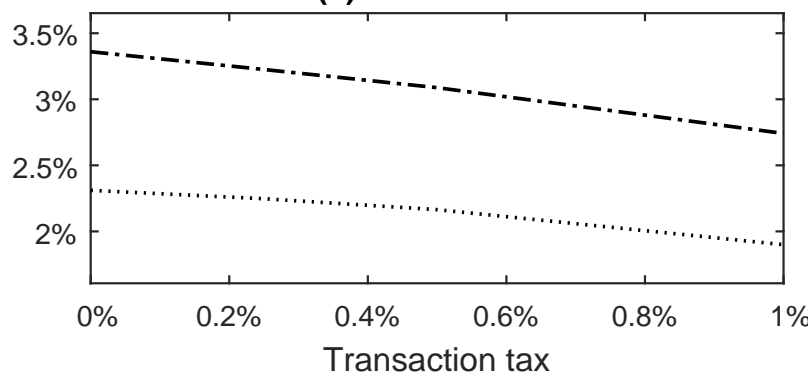

(c) Levered stock return volatility

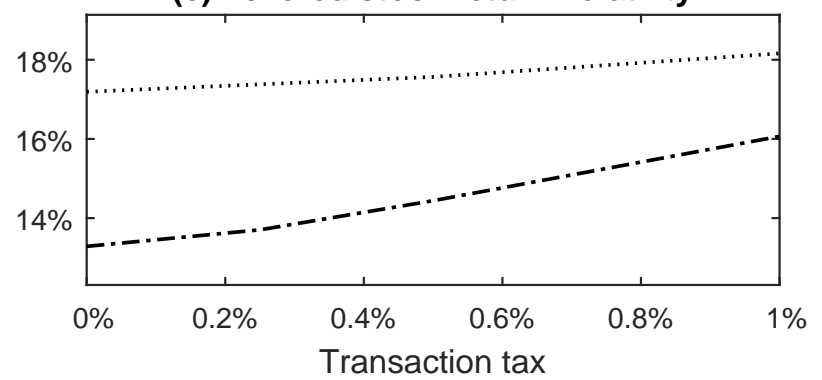

(e) Stock turnover

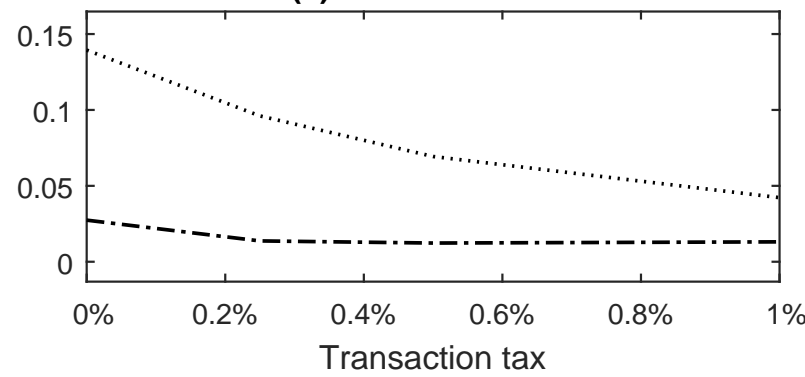

(g) Output growth

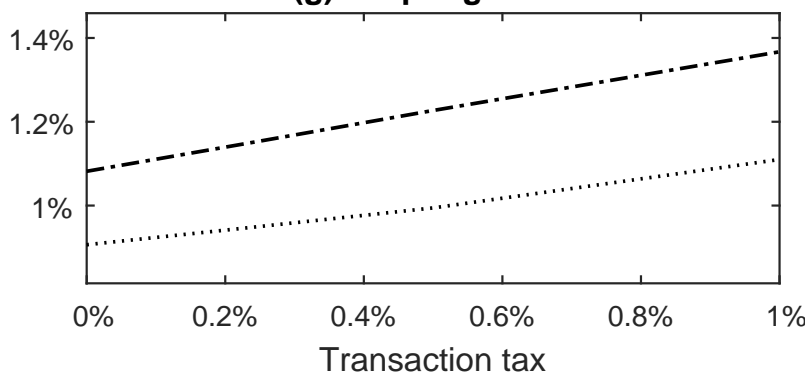

(b) Levered equity premium

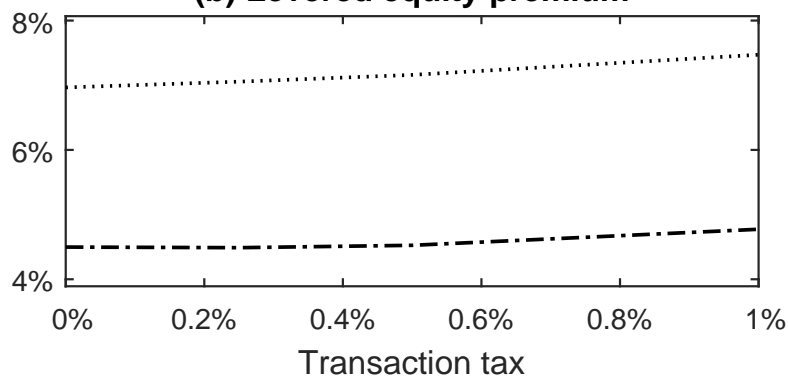

(d) Bond turnover

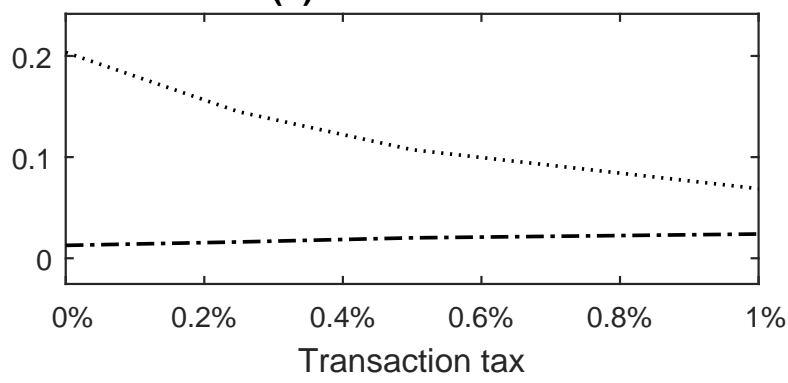

(f) Capital investment (\%output)

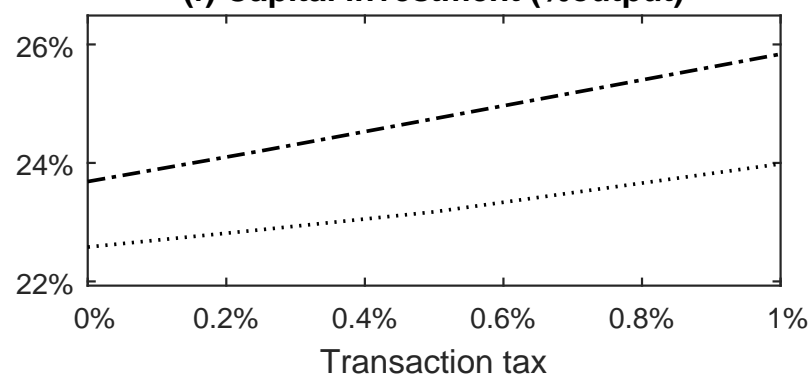

(h) Welfare

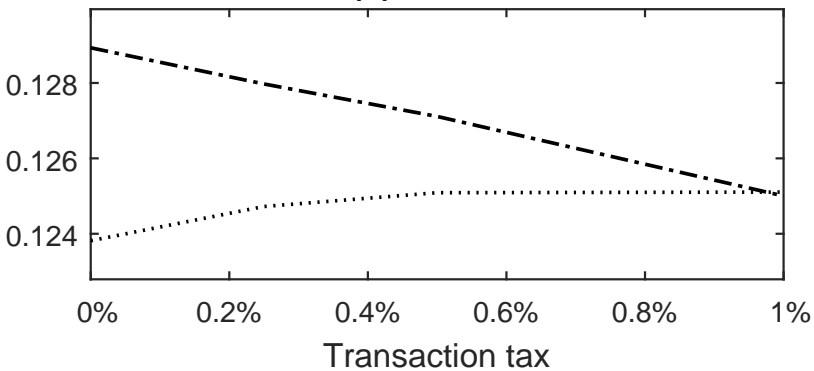

With Disagreement -----Without Disagreement

The eight panels in this figure show how a Tobin financial-transaction tax on trading the stock affects various financial and macroeconomic quantities. The dotted line is for the economy with disagreement between the two classes of investors and the dash-dotted line is for the economy without disagreement. 


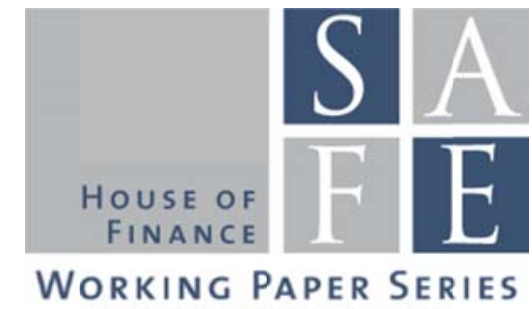

\section{Recent Issues}

No.123 Marie Lalanne, Paul Seabright

No. 122 Douglas Cumming, Uwe Walz, Jochen Werth

No. 121 Elia Berdin, Matteo Sottocornola

No. 120 Matthias Heinz, Heiner Schumacher

No.119 Michael Brennan, Holger Kraft

No. 118 Michael Donadelli, Antonio Paradiso, Max Riedel

No. 117 Marcel Bluhm

No. 116 Charles Gottlieb

No. 115 Andreas Fagereng, Charles Gottlieb, Luigi Guiso

No. 114 Nicole Branger, Christian Schlag, Lue $\mathrm{Wu}$

No. 113 Bettina Brüggemann, Jinhyuk Yoo

No. 112 Shafik Hebous, Alfons J. Weichenrieder

No.111 Alfons J. Weichenrieder, Fangying $\mathrm{Xu}$

No. 110 Dirk Krueger, Alexander Ludwig

No. 109 Tobias Tröger
The Old Boy Network: The Impact of Professional Networks on Remuneration in Top Executive Jobs

The Dynamics of Entrepreneurial Careers in High-Tech Ventures: Experience, Education, and Exit

Insurance Activities and Systemic Risk

Signaling Cooperation

Leaning Against the Wind: Debt Financing in the Face of Adversity

A Quasi Real-Time Leading Indicator for the EU Industrial Production

Interbank Funding as Insurance Mechanism for (Persistent) Liquidity Shocks

On the Distributive Effects of Inflation

Asset Market Participation and Portfolio Choice over the Life-Cycle

'Nobody is Perfect': Asset Pricing and Long-Run Survival When Heterogeneous Investors Exhibit Different Kinds of Filtering Errors

Aggregate and Distributional Effects of Increasing Taxes on Top Income Earners

On Deficits and Symmetries in a Fiscal Capacity

Are Tax Havens Good? Implications of the Crackdown on Secrecy

On the Optimal Provision of Social Insurance

Regulatory Influence on Market Conditions in the Banking Union 